\title{
Mainstreaming emergency contraception in Kenya: Final project report
}

\author{
Jill Keesbury \\ Population Council \\ Wilson Liambila \\ Population Council \\ Francis Obare \\ Paul Kuria
}

Follow this and additional works at: https://knowledgecommons.popcouncil.org/departments_sbsr-rh

Part of the Demography, Population, and Ecology Commons, Family, Life Course, and Society

Commons, Gender and Sexuality Commons, International Public Health Commons, and the Medicine and Health Commons

How does access to this work benefit you? Let us know!

\section{Recommended Citation}

Keesbury, Jill, Wilson Liambila, Francis Obare, and Paul Kuria. 2009. "Mainstreaming emergency contraception in Kenya: Final project report," Final Project Report. Nairobi: Population Council. 


\section{Mainstreaming Emergency Contraception in Kenya}

Final Project Report

(2) 


\title{
Mainstreaming Emergency Contraception in Kenya
}

\section{Final Project Report}

\author{
2009 \\ Population Council, Nairobi \\ and \\ Population Services International, Kenya \\ jill Keesbury \\ Wilson Liambila \\ Francis Obare \\ Paul Kuria
}




\section{TABLE OF CONTENTS}

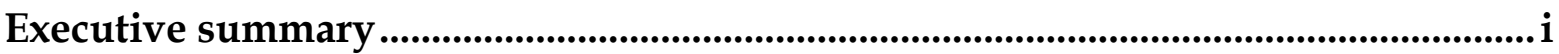

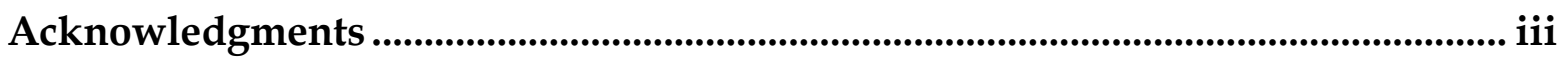

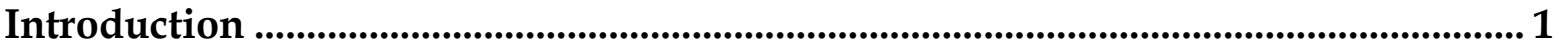

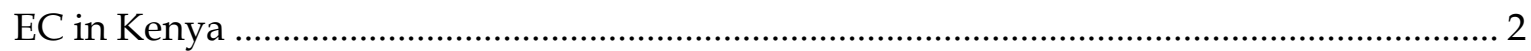

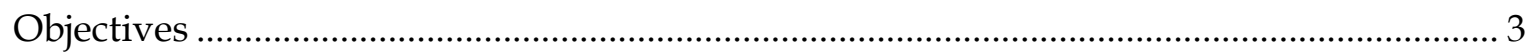

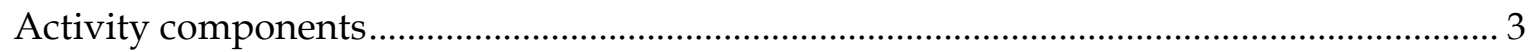

Component 1: Awareness creation .......................................................................................... 4

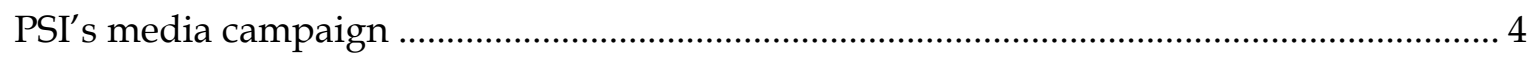

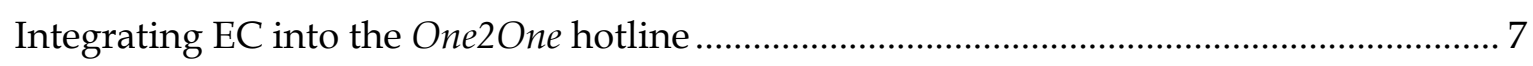

Responding to negative information in the media................................................................ 9

Component 2: Strengthening EC in the private sector ......................................... 10

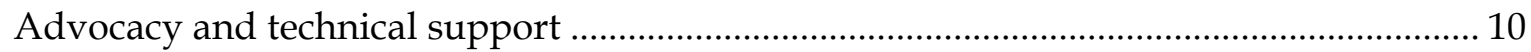

Client intercept study: Who buys EC from pharmacies? ....................................................... 11

Intervention study: Towards a strategy for bridging ........................................................ 12

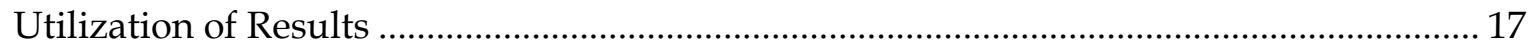

Component 3: Strengthening EC in the public sector ................................................ 18

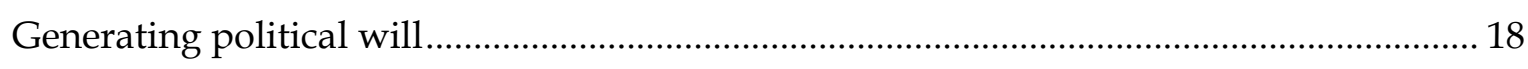

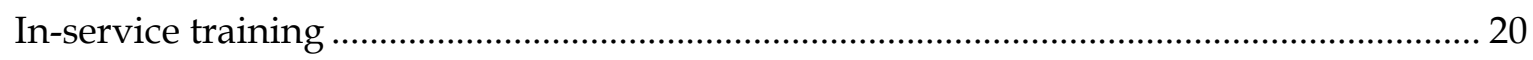

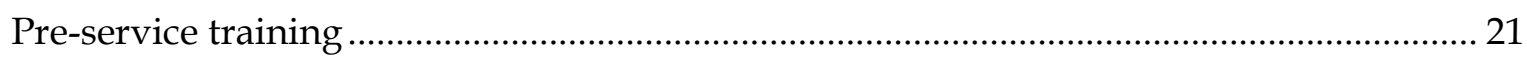

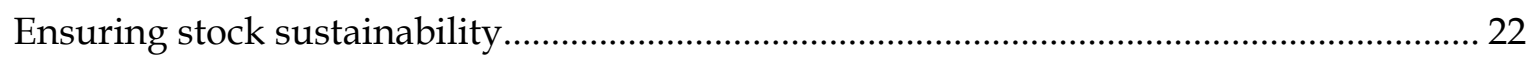

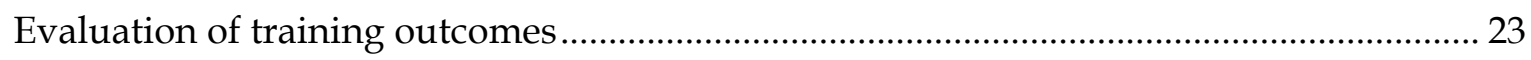

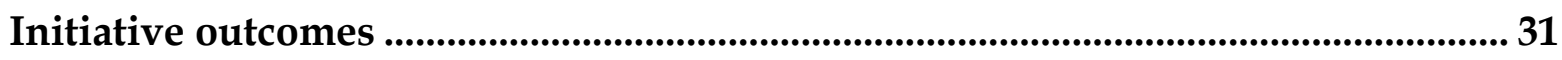

Increased knowledge and use of EC among Kenyan women ............................................. 31

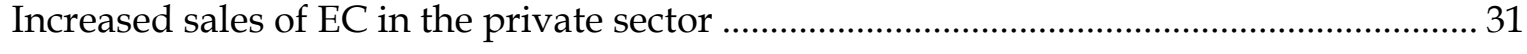

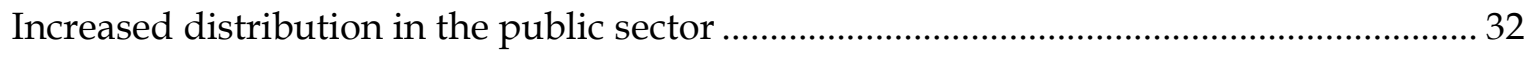

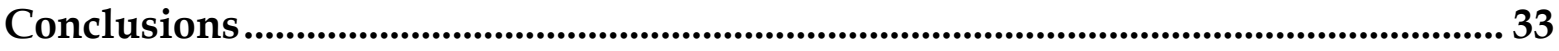

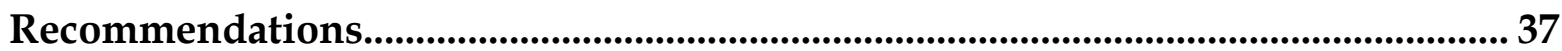




\section{EXECUTIVE SUMMARY}

In late 2006, the Kenyan Ministry of Public Health and Sanitation (MOPHS) ${ }^{1}$, Population Council and Population Services International (PSI) launched an initiative to mainstream emergency contraception (EC) in Kenya. The initiative included a core set of activities aimed at improving overall awareness of EC across the country and strengthening the quality of EC services in both the public and private sectors. It was intended to serve as a model for other countries interested in improving access to EC, and to generate in-depth knowledge on EC program strategies and utilization characteristics in Sub-Saharan Africa.

The specific objectives of the initiative were to:

- Increase knowledge, awareness and correct use of EC among Kenyan women aged 18-30 years;

- Increase knowledge and awareness of EC among providers and pharmacists;

- Strengthen EC provision in both the private and public sectors.

To achieve these objectives, activities were jointly undertaken to increase public awareness through a national media campaign (undertaken by PSI), develop strategies to improve the quality of EC services in the private sector (undertaken jointly by Population Council and PSI) and strengthen EC provision in the public sector (undertaken jointly by the $\mathrm{MOH}$ and the Population Council).

By the conclusion of the initiative, public awareness of EC had doubled, sales in the private sector had more than trebled and public sector utilization also increased tremendously. Overall knowledge among providers increased significantly over the life of the initiative, and those trained on $\mathrm{EC}$ under the $\mathrm{MOH}^{\prime}$ s Contraceptive Technology Updates series demonstrated more favorable attitudes and practices toward EC. Provider capacity was also increased in the private sector through an innovative, non-invasive strategy to improve information provision in pharmacies. On a national level, the pre-service training curriculum for nurses was updated to include $\mathrm{EC}$ and the $\mathrm{MOH}$ has revised national guidelines based on the experiences of this initiative.

Among the key lessons learned from the initiative are:

- Even negative media coverage on EC can be used effectively.

- Awareness and use of EC has increased dramatically in Kenya, but still remains low.

- Private sector pharmacies dominate the provision of EC in Kenya.

- The majority of women who purchase EC from pharmacies are educated and employed.

\footnotetext{
${ }^{1}$ In 2008, this program was transferred from the Ministry of Health (MOH) to the newly-created Ministry of Public Health and Sanitation (MOPHS).
} 
- Some Kenyan women have used EC more than once in a month, but repeat users are less informed about the method.

- Pharmacies can provide better EC services with minimal investment.

- Integrating EC into existing pre-service and in-service training programs can enhance public sector provision.

- Active advocacy is necessary to ensure adequate EC stocks in the public sector.

In order to sustain and consolidate the positive developments realized under the initiative, it is necessary that:

- Efforts to create public awareness and correct knowledge of EC should be continued.

- Professional associations, including the Pharmaceutical Society of Kenya and the Kenya Pharmaceutical Association, should continue educating their members on proper EC provision.

- All MOPHS training partners should ensure that EC is integrated into all trainings on family planning, reproductive health, adolescent health or postrape care.

- All pre-service training institutions and bodies should include EC provision in their curricula and examinations.

- The MOPHS, donors and partners should continue to ensure that adequate EC supplies are available in the public sector.

- All stakeholders should promote the Kenyan experience as a model for the region. 


\section{ACKNOWLEDGMENTS}

We wish to acknowledge individuals and a number of institutions and organizations in Kenya who have over the years made it possible to achieve the results outlined in this report. In particular we wish to thank the Nursing Council of Kenya, Clinical Officers Council, Division of Reproductive Health (DRH) in the Ministry of Public Health and Sanitation (MOPHS), Kenya Medical Supplies Agency (KEMSA), major distributors of EC brands in Kenya, Population Services International, Liverpool VCT Care and Treatment, Pharmaceutical Society of Kenya, Pharmacy and Poisons Board and other institutions including NGOs, CBOs, partners in the USAIDsupported APHIA II program, and provincial health management teams for having played different roles during the planning, implementation and evaluation phases of the project on mainstreaming EC in Kenya.

This initiative was made possible through the generous support of the William and Flora Hewlett Foundation, which has shown true leadership and vision in promoting EC across the world. The United Nations Population Fund (UNFPA) in Kenya also provided technical and financial assistance for work under this initiative, and has served as an active advocate for EC mainstreaming in the country. A generous donation from an interested individual is also highly appreciated. 


\section{INTRODUCTION}

For over a decade, advocates have sought to improve access to emergency contraception (EC) across the world. These efforts have been highly successful in Europe and North America, where EC is now widely available over the counter, have generated much debate in Latin America, and are beginning to take hold in Asia.

In Africa, however, the success of EC programs remains limited. Even in countries where the regulatory environment is favorable, resource constraints within the public sector limit the ability to provide consistent and quality EC services at low cost. In a growing number of African countries, the private sector has emerged to fill these gaps, increasing access primarily among young, affluent urbanites. Low knowledge levels among the general population ultimately undermine the impact of such provision strategies, with as few as $10 \%$ of women in Senegal and Zambia reporting having ever heard of EC, and in the majority of African countries, less than one percent of all women have reported ever using it (Table 1).

Table I: EC Knowledge and Use in African Demographic and Health Surveys (DHS)

\begin{tabular}{|l|l|l|l|l|}
\hline \multirow{2}{*}{ Country } & \multirow{2}{*}{ Year of DHS } & \multicolumn{2}{|c|}{ Knowledge } & \multirow{2}{*}{ Ever Use } \\
\cline { 3 - 4 } & & \multicolumn{2}{|c|}{ Women } & \multicolumn{2}{|c|}{ Men } \\
\hline Nigeria & 2003 & 15.7 & 27.9 & 2.8 \\
\hline Ghana & 2003 & 28.2 & 29.7 & 1.1 \\
\hline Malawi & 2004 & 26.3 & 21.6 & 0.3 \\
\hline Kenya & 2003 & 23.7 & $\mathbf{2 5 . 6}$ & $\mathbf{0 . 9}$ \\
\hline Senegal & 2005 & 9.6 & 16.0 & 0.2 \\
\hline Zambia & 2001 & 9.4 & 1.8 & 0.5 \\
\hline
\end{tabular}

In 2006, the Kenyan Ministry of Health $(\mathrm{MOH})^{2}$, Population Council and Population Services International (PSI) launched an initiative intended to overcome these barriers to access.

The initiative included a core set of activities aimed at improving overall awareness of EC across the country and strengthening the quality of EC services in both the public and private sectors. It was intended to serve as a model for other countries interested in improving access to EC, and to generate in-depth knowledge on EC program strategies and utilization characteristics in Sub-Saharan Africa. This report details the outcomes of this initiative.

\footnotetext{
2 In 2008, this program was transferred from the Ministry of Health (MOH) to the newly-created Ministry of Public Health and Sanitation (MOPHS).
} 


\section{EC in Kenya}

Kenya has been a pioneer in the EC field. It was one of the first countries in Africa to introduce EC into its private and public sectors, and has benefitted from several programs intended to increase access to the method. As early as 1992, the dedicated product Postinor was registered in Kenya and distributed in select pharmacies and health outlets, and in 1997 the next generation product, Postinor-2 was introduced into the Kenyan market. The impact of these efforts can be seen in Table 1, with Kenya demonstrating comparatively high levels of EC knowledge and use, although still representing a small minority of the population.

In 1996 the International Consortium for Emergency Contraception (ICEC) identified Kenya as a priority country for an EC introduction campaign. Partners in this broadbased initiative included the $\mathrm{MOH}$, a local NGO (Family Planning Association of Kenya), International NGOs (Pathfinder International, Population Council and PATH), the University of Nairobi (Department of Obstetrics and Gynecology) and the local Postinor-2 distributor (Globe Pharmacy). Together, these partners primarily focused on improving the capacity of the public sector to provide EC services through advocacy, training and materials development. As a result, EC was officially included in the National Family Planning Guidelines, and provider knowledge in intervention areas increased significantly by the conclusion of the project. $^{3}$

In the ensuing years, supply irregularities and competing interests in the increasingly competitive family planning (FP) sector lessened the emphasis placed on EC. By the mid-2000s, however, increased attention to post-rape care reinvigorated interest in the method. In 2005, with assistance from the United Nations Population Fund (UNFPA), the MOH procured 700,000 units of Postinor 2 for distribution in public sector facilities. The national roll-out, supported by the Population Council's ECafrique regional consortium, included a two-day workshop on EC for senior health planners and policy makers from all of Kenya's eight provinces. Building on this momentum, Marie Stopes Kenya launched a program to socially market the Indian-manufactured EC product, Pregnon, in its affiliated clinics, helping to further diversify the market.

As access to EC expanded, most notably in the private sector, concerns over potential "misuse" of EC by young women emerged in the public debate. In 2004, Kenya's leading newspaper published an article claiming that girls were eating EC "like chocolates" and engaging in risky, unprotected sex. ${ }^{4}$ Despite the publication of several subsequent informed responses, public perception continued to associate increased access to EC with risky sexual behavior. ${ }^{5}$

\footnotetext{
${ }^{3}$ Muia, E. Blanchard, K. Lukhando, M. Olenja, J. Liambila, W. 2002. “Evaluation of an emergency contraception introduction project in Kenya." Contraception (66): 255-260.

${ }^{4}$ Okwemba A and Anyona J, Having fun with morning-after pills, Daily Nation, 13 May 2004, 25-26

5 Teens and the morning-after pill, Daily Nation. 22 June 2006.
} 
In this context, the Population Council and PSI launched an initiative to support the $\mathrm{MOH}$ 's renewed commitment to providing EC at the national level and to strengthen private sector provision, while at the same time addressing public fears associated with its increased access.

\section{Objectives}

Overall, the initiative aimed to increase knowledge and use of EC in Kenya through a combination of strategies focusing on both the private and public sectors. Implemented jointly by Population Council and PSI, specific objectives included:

- Increased knowledge, awareness and use of EC among Kenyan women aged 18-30 years;

- Increased knowledge and awareness of EC among providers and pharmacists;

- Strengthened capacity of public and private sector health facilities and pharmacies to provide both emergency and regular contraceptives.

\section{Activity components}

To achieve these objectives, three sets of activities were undertaken:

- Awareness creation campaigns, consisting of radio, television and print media spots conducted by PSI with evaluation support provided by the Council.

- Private sector support, including an intervention study to improve service quality within the pharmacies (Population Council) and development of point-of-sale informational materials (PSI).

- Public sector support, including integrating EC into existing training programs and pre-service curricula, advocating for the repositioning of EC as a component of adolescent reproductive health (RH) services, ensuring stock sustainability and developing provider reference materials. (Population Council)

The results of each set of activities are detailed below. 


\section{COMPONENT I:AWARENESS CREATION}

At the core of this initiative were efforts to increase public awareness of EC. As highlighted in Table 1, the 2003 DHS indicated that less than one quarter of Kenyan women had ever heard of EC. Baseline research undertaken by PSI four years later found similar patterns, with only $21 \%$ of women reporting having ever heard of EC. Of those, only $15 \%$ could correctly identify EC as a contraceptive method taken after sex to prevent pregnancy. ${ }^{6}$ By the conclusion of the initiative, however, $56 \%$ of women surveyed had ever heard of EC and $10 \%$ of them had ever used the method.

Table 2: Knowledge and use of EC in Kenya, DHS and PSI baseline surveys

\begin{tabular}{|l|c|c|c|}
\hline Source & Year & $\begin{array}{c}\text { Ever heard of EC } \\
\text { (women) }\end{array}$ & Ever use \\
\hline DHS & 2003 & $24 \%$ & $0.9 \%$ \\
\hline PSI baseline $(n=675)$ & 2007 & $21 \%$ & $5 \%$ \\
\hline PSI endline $(n=1252)$ & 2009 & $56 \% *$ & $10 \% *$ \\
\hline
\end{tabular}

$* p=<0.05$, comparing 2007 to 2009 results, after controlling for age, socioeconomic and marital status

Significant changes were seen in knowledge and use between the 2007 baseline survey and the 2009 endline evaluation, with both indicators doubling during the two year period. This finding does lend some support to the public perception that $\mathrm{EC}$ use is on the rise. It does not, however, confirm the media's contention that young women were eating EC "like chocolates." 7

\section{PSI's media campaign}

Drawing on the baseline findings, PSI launched Tulia ("relax" in Kiswahili), a national media campaign designed to: 1) increase awareness of EC among women 18-30; and 2) increase knowledge needed to make informed decisions about EC use.

Communication efforts were structured around the following three key messages:

- EC can prevent pregnancy after unprotected sex;

- EC does not protect against HIV or STI infection;

- EC should be used only as an emergency method and not as a regular form of contraception.

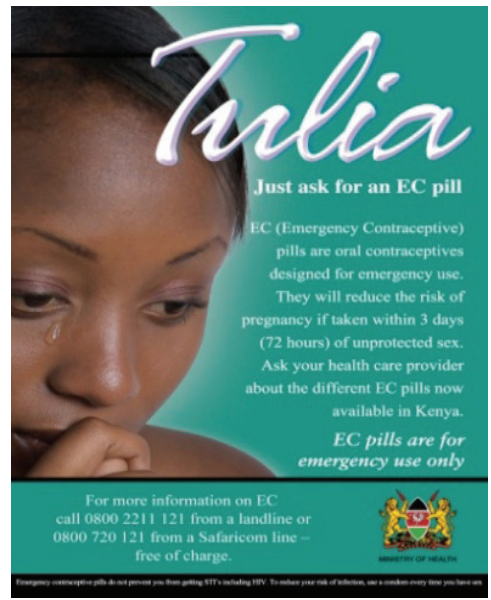

The media campaign began in May 2008, although it was quickly suspended by the national Pharmacy and Poisons Board (PPB) due to legal restrictions on advertizing

\footnotetext{
${ }^{6}$ Morgan, G. August 28, 2007. Private Sector EC Use: A Profile of EC Users. Presentation delivered at the Kenya DRH/MOH EC Data Interpretation Workshop, Nairobi.

7 Okwemba A and Anyona J, Having fun with morning-after pills, Daily Nation, Nairobi, Kenya, 13 May 2004, 25-26.
} 
hormonal contraceptives. Following months of intensive lobbying by PSI and the Population Council, the PPB approved slight revisions in the campaign which resumed in October 2008. The campaign consisted of:

- Radio advertisements on national and regional radio stations

- Radio call-in talk shows

- EC inserted into the story lines of two local soap operas

- Community outreach events to reach local young women in 7 regions

- Print articles in the Standard and Daily Nation newspapers, and in Parents magazine

In February 2009, ECafrique was invited to host a plenary session on EC at the East, Central and Southern African Obstetrics and Gynecology Society (ECSAOGS) conference held in Mombasa, Kenya. During this session, Kenyan participants vigorously debated the content of the Tulia campaign. Concerns were raised regarding the radio messages, which some participants felt were culturally inappropriate. They were interpreted as a mother speaking to a daughter (rather than friend to friend), which many participants were uncomfortable with. It was also suggested that the timing of the advert be changed from weekday mornings, when many parents and children listen to the radio together, to a slot that was more targeted toward the youth. Participants also suggested that the time period in the adverts be updated to reflect current $\mathrm{MOH}$ guidance of 120 hours rather than the 72 hours recommended by most manufacturers. These comments were reported back to PSI which took steps to address the issues raised at the conference.

\section{Results: Increased knowledge and awareness}

To measure the impact of the Tulia media campaign, PSI undertook nationallyrepresentative surveys at baseline and endline. In March 2007, the baseline survey was implemented in 13 major towns and surrounding peri-urban areas in seven of the eight provinces in Kenya. The study used a rapid, expanded immunization sampling strategy. A total of 675 women aged 18-30 years were surveyed at the household level. In August 2009, an endline survey was implemented in the same towns where the baseline survey took place. The household survey was comparable in design and execution to the baseline survey, which allowed for comparability. A total of 1,252 women were interviewed in 2009.

As indicated in Table 2, both knowledge and use of EC increased dramatically in the period between 2007 and 2009. Table 3 demonstrates that, among those women that had heard of EC, significant improvements were also seen in key knowledge and attitude variables from baseline to endline. In 2009, women who knew of EC were more likely to believe that their partner would approve EC use, indicating growing social acceptance of the method. Data also demonstrates greater knowledge of where EC can be obtained, with $11 \%$ more women noting that it was available in pharmacies, and 9\% identifying health clinics as an outlet. Knowledge that EC does not protect from STIs or HIV was uniformly high in both surveys, highlighting the fact that most women are fully informed about the risks in using EC. Very 
interestingly, the proportion of women who know that EC should be taken within 72 hours decreased from baseline to endline. This suggests that more emphasis needs to be placed on increasing correct knowledge of the method as well as improving overall awareness.

Table 3: Key knowledge and attitude variables among women who had ever heard of EC

\begin{tabular}{|l|l|l|}
\hline & $\begin{array}{l}\text { Baseline } \\
\mathbf{N = 1 3 0}\end{array}$ & $\begin{array}{l}\text { Endline } \\
\mathbf{N}=\mathbf{5 2 2}\end{array}$ \\
\hline \% of women agreeing "my partner would approve of the use of EC" & 47 & $56^{*}$ \\
\hline Where is EC available? † & & \\
\hline \multicolumn{1}{|c|}{ Pharmacies } & 72 & $83^{*}$ \\
\hline $\begin{array}{l}\text { \% of women who strongly agree that EC does NOT protect from } \\
\text { STls or HIV }\end{array}$ & 16 & 25 \\
\hline EC does not cause abortion & 92 & 91 \\
\hline EC should be taken within 72 hours $^{8}$ & 60 & 63 \\
\hline
\end{tabular}

† Multiple responses allowed; estimates are controlled for age, socioeconomic and marital status. $* \mathrm{p}=<0.05$

An important element of the public debate on EC is its use as a regular family planning method. As discussed more fully below, the Kenyan media has asserted that women routinely use EC as their primary contraceptive method. To gain insight into this issue, the endline survey asked respondents to agree or disagree with the statement "EC should NOT be used as a regular form of family planning." Table 4 reviews responses to this question, looking specifically at those who strongly agreed with the statement. Whereas $66 \%$ all women agreed that EC should not be a regular method, proportions were significantly higher for those that had been exposed to the Tulia campaign. This suggests that Tulia campaign was effective in reaching audiences with this message.

\footnotetext{
${ }^{8}$ At the time this research was conducted, National Family Planning Guidelines indicated that EC should be taken within 72 hours of unprotected sex. This has subsequently been changed to 120 hours in the 2010 revision of the Family Planning Guidelines.
} 
Table 4: Proportion of women who strongly agree EC should NOT be used as a regular form of family planning

\begin{tabular}{|l|c|}
\hline $\begin{array}{l}\text { Proportion of women who strongly agree EC should NOT } \\
\text { be used as a regular form of family planning }\end{array}$ & $\%$ \\
\hline All endline respondents $(n=522)$ & 66 \\
\hline By campaign exposure & $78^{*}$ \\
\hline Exposed to Tulia campaign $(n=1649)$ & 66 \\
\hline Not exposed to Tulia campaign $(n=87)$ & \\
\hline
\end{tabular}

The endline survey also explored the issue of "bridging" EC users to other family planning methods. Among women who have ever used EC, 46\% reported starting to use a routine form of contraception after the last time they obtained EC. The proportion was even higher among those that received family planning counseling from providers the last time they obtained EC, with 50\% reporting "bridging" to a regular form of contraception. While much more needs to be known about the dynamics of this transition, the findings do indicate that EC does not constitute the only method of family planning for about half of the users surveyed.

\section{Integrating EC into the One2One hotline}

In addition to raising awareness of EC, the initiative also worked to increase correct knowledge of the method. In support of this objective, the Population Council collaborated with Liverpool VCT, Care and Treatment (LVCT) to integrate EC into their existing youth sexuality hotline, One2One. PSI included the telephone number on their posters and print informational materials.

In collaboration with the MOH, PSI and the Kenya Association of Professional Counselors, the Council conducted a one-day training for all nine of LVCT's hotline counselors in October 2007. The training provided a basic introduction to how EC works and where it can be obtained, reviewed the results of PSI's baseline research on use patterns, and discussed issues of "bridging" EC users to other RH services such as regular contraception, VCT or post-rape care. In December 2008, these counselors were provided with refresher training.

The Council also supported LVCT's record-keeping activities by revising their recording form to include EC and providing data entry assistance. Reliable data were collected from January 2008 until April 2009.

Before February 2009, the toll-free One2One hotline was only reachable from a landline; as a result, very few youth contacted the hotline with EC questions. In early 2009, LVCT added a mobile phone number to their service and in March PSI added that number to their campaign materials. Immediately thereafter, the number of calls on EC dramatically increased from 3\% of all calls in 2008 (5 calls) to 18\% by 2009 (347 
calls) (Figure 1). This indicates both the importance of mobile phone numbers for reaching youth and the penetration of PSI's media campaign.

Figure I: Number of EC calls to One2One hotline, January 2008- April 2009

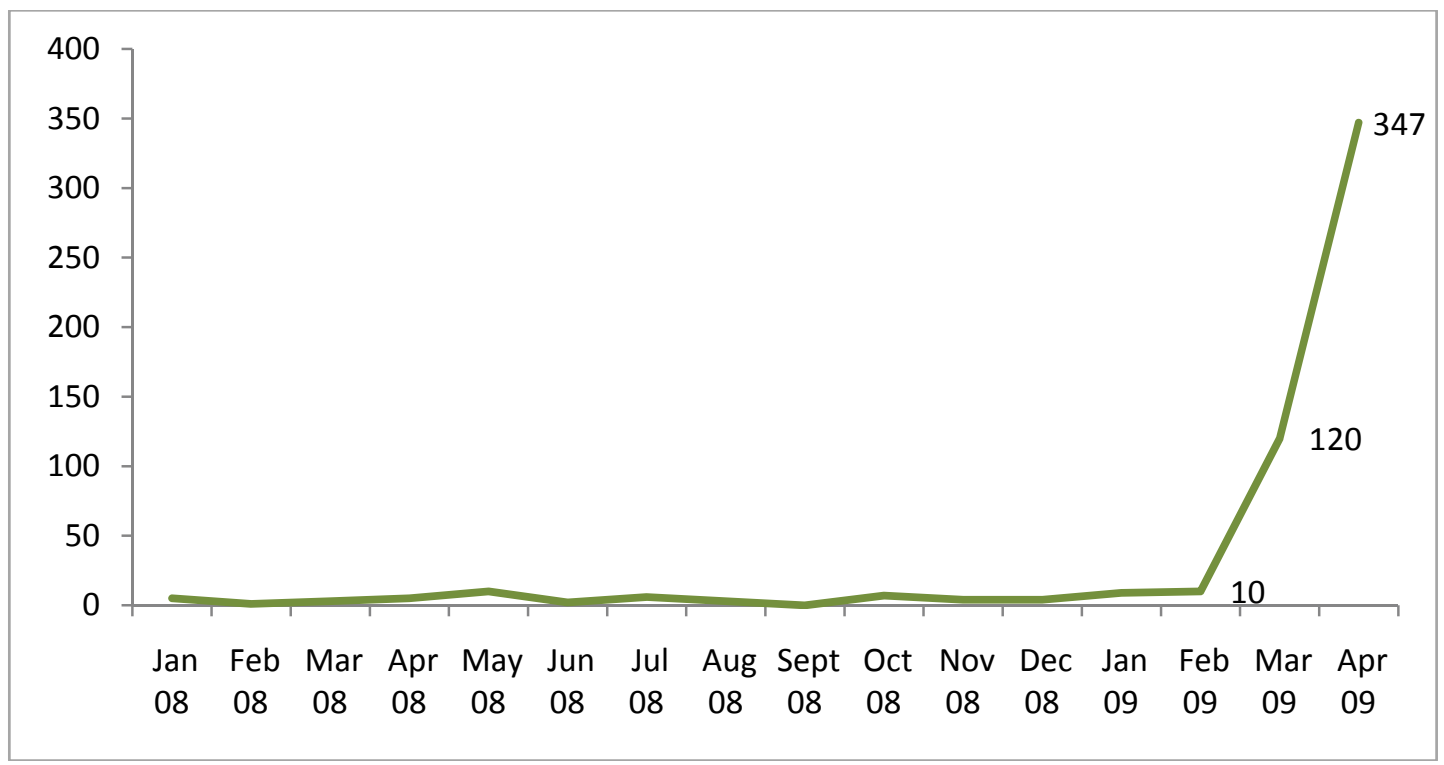

The majority of callers to the hotline were female $(65 \%)$, although a substantial number of men $(35 \%)$ called for more information on EC. Most callers (82\%) were under 24 years, and of these, the majority (78\%) was between 19-24 years old. About one-fifth of callers were aged 25 years and above. As noted below, this age distribution is slightly lower than that found in a self-reported survey of pharmacy users, whose mean reported age was 25 . Nonetheless, the data indicates that young adults, not young adolescents, currently constitute the largest group of EC users in Kenya.

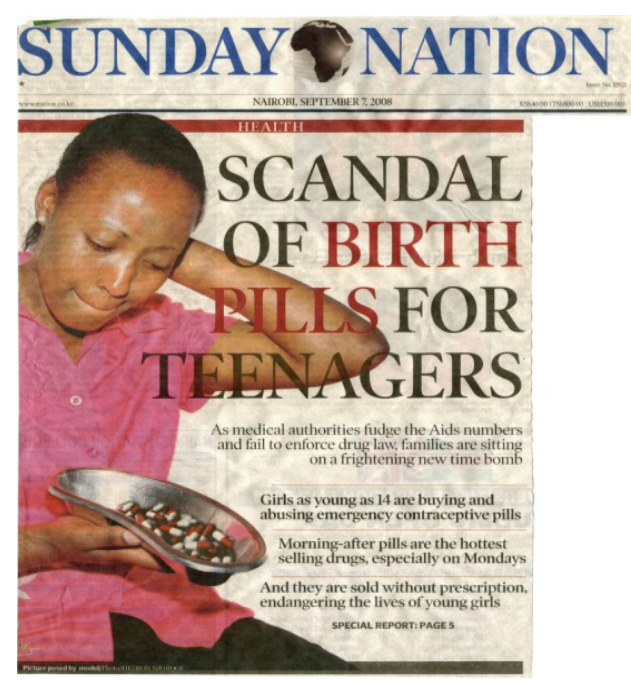




\section{Responding to negative information in the media}

Increased awareness of EC was also reflected in media reporting, although not all of such reports were favorable or accurate. As noted above, in 2004 the Daily Nation published its first feature story on EC. Since then, EC has become a favorite of the media houses, routinely publishing sensationalized articles on the 'epidemic' of misuse among young women (Table 5).

Table 5: EC in the Kenyan Media

\begin{tabular}{|l|l|l|c|c|}
\hline Article title & Publication & Date & Negative & Positive \\
\hline Having fun with morning-after pills & Daily Nation & I3 May 2004 & X & \\
\hline Alarm over morning-after pill & Daily Nation & 24 Oct 2005 & X & X \\
\hline $\begin{array}{l}\text { Enough hysteria over the morning- } \\
\text { after-pill }\end{array}$ & $\begin{array}{l}\text { Daily Nation, Letter } \\
\text { to the editor } \\
\text { (ECafrique) }\end{array}$ & 5 Nov 2005 & & X \\
\hline Teens and the morning-after pill & $\begin{array}{l}\text { Daily Nation } \\
\text { (coverage of } \\
\text { ECafrique study) }\end{array}$ & 22 June 2006 & & X \\
\hline $\begin{array}{l}\text { When it's time to swallow } \\
\text { morning after pills }\end{array}$ & $\begin{array}{l}\text { Sunday Nation, Op- } \\
\text { ed (Sarah Onyango, } \\
\text { PPFA) }\end{array}$ & 24 June 2007 & X & \\
\hline $\begin{array}{l}\text { Scandal of morning after pills for } \\
\text { teens }\end{array}$ & Sunday Nation & 2 Sept 2008 & X & \\
\hline Kenya concern over pill-popping & BBC & 14 July 2009 & X & \\
\hline $\begin{array}{l}\text { You've seen it on TV. Think } \\
\text { before you act }\end{array}$ & Standard & 2009 & & \\
\hline
\end{tabular}

The Population Council and PSI have worked together to counter this negative media attention. In addition to publishing responses and placing positive articles, the Council also actively lobbied with stakeholders to ensure that such stories did not limit access to EC. The 2008 "scandal" cover story generated the most debate within the public sector, although many key officials saw it as indicating the need for more public awareness on EC. In response, one senior MOH official, Dr. Shahnaaz Sharif, the then Head of Technical Services, admitted "I think we have not adequately explained to the community that the morning-after pill should be used only in situations where people have accidentally had unprotected sex or in the case of sexual coercion".

Most recently, the $\mathrm{MOH}$, with support from the Council, PSI and the ICEC, issued a press release to respond to the 2009 BBC article. This press release addressed the article's factual inaccuracies, and responded to allegations that easy access to EC threatened to undermine the country's HIV prevention activities. With this article, and a subsequent one published in the Standard, the discourse has shifted away from the concern that EC promoted promiscuity to associating it with increased HIV risk. Interestingly, in Kenya, EC has not been consistently or convincingly linked with abortion. 


\section{COMPONENT 2: STRENGTHENING EC INTHE PRIVATE SECTOR}

During project planning, private sector pharmacies were identified as an important outlet for EC. It was not until implementation, however, that the magnitude of their role was identified. Qualitative formative research identified pharmacies as the primary point for EC access, and PSI's baseline survey confirmed that $95 \%$ of those who had ever used EC purchased it from a private sector pharmacy. Media reports, although sensationalized, also contended that most young women prefer to purchase EC from pharmacies. All sources indicated that these women lacked the basic information needed to make informed decisions about EC use.

In light of this evidence, the Council intensified its activities to strengthen private sector provision. It worked closely with pharmacists, distributors, regulatory bodies and professional associations to address emerging issues and concerns associated with increased demand for EC services. The Council also undertook two studies aimed at improving EC services within pharmacies, contributing to the underdeveloped literature on private sector provision of health care services.

\section{Advocacy and technical support}

Private sector pharmacists, like the media and general public, have expressed discomfort with the growing demand for EC and shared perceptions of misuse. To ensure continued access and improve pharmacists' comfort with the method, the Council has actively engaged with the Pharmaceutical Society of Kenya (PSK). In early 2008, the Council and PSI jointly convened a meeting of PSK's executive committee to respond to concerns regarding the Tulia campaign. The support garnered from this and subsequent meetings helped secure eventual approval for the campaign's re-launch. PSK members were also actively involved in the design and implementation of the intervention study described below, and with support from PSI, results were formally disseminated to the membership in September 2009.

The Council is increasingly recognized as an independent advocate for EC, and has worked collaboratively with competing interests to ensure consistent supply. Marie Stopes Kenya approached the Council for assistance in identifying and obtaining additional financial support for EC activities in Kenya. As a result of active lobbying undertaken by the Council and the Hewlett Foundation, Marie Stopes London provided an additional year of funding for the SmartLady branded EC social marketing campaign. The Council also worked with the Pharmacy and Poisons Board and the local distributor of Postinor 2, Globe Pharmacy, to react to counterfeit supplies on the market. To address this issue, the PPB published an advertisement in prominent national newspapers alerting users and distributors of the danger posed by counterfeit EC pills.

The Council was also able to negotiate regular access to sales data for purposes of monitoring this initiative. As a result of successful advocacy and relationshipbuilding, the Council obtained highly-sensitive monthly sales figures for the four 
leading brands sold in Kenya: Postinor-2, ECee2, Truston and SmartLady. These data indicate an overall increase in the units of EC sold over the life of the initiative, and is presented in the concluding section of this report.

\section{Client intercept study: Who buys EC from pharmacies?}

The Council produced evidence to inform advocacy and program activities. It undertook a series of studies to understand the dynamics of pharmacy access, beginning with a client intercept study which focused on describing the characteristics and use patterns of women who purchase EC in pharmacies. ${ }^{9}$

\section{Methods}

The study was undertaken in August 2007 in selected pharmacies from the main towns in five provinces: Nairobi, Coast, Rift Valley, Nyanza and Western. Each town was represented by a residential and town-center sample. Selection of streets was purposive to cater for pharmacies serving clients within a wide socioeconomic range. All clients seeking EC pills from sampled pharmacies were approached for inclusion in the study. A total of 182 clients were interviewed, 147 of whom were women buying EC for their own use.

At each pharmacy where interviews were conducted, providers and their assistants were given a card with a free help-line number asking them to call if they had any questions on EC. Upon purchase of EC, all clients were also given the card by a pharmacy assistant and then requested to talk to an interviewer who was located in a semi-private area inside or outside the pharmacy, depending on space available.

\section{Client characteristics}

The data dispels the Kenyan media's contention that EC is generally a preserve of young adolescents. Clients in this sample were more likely to be in a marital, cohabitating, or other regular relationship, college or university graduates, in their mid 20s, and engaged in some income-earning activity. Unmarried women (regardless of age) having sex on a regular basis were especially likely to be repeat users and to hold favorable attitudes towards use of EC as a regular method of FP.

The average age of clients was 25 years, with the majority between $20-29$ years (72\%). Most clients had a college/university level of education (61\%) and 61\% were currently employed (including self-employment). About two-thirds (65\%) were either married/cohabiting or single but in a steady relationship. Less than half $(41 \%)$ reported having at least one child.

\footnotetext{
${ }^{9}$ Keesbury J, Morgan G, Owino B. Is repeat use of emergency contraception common among pharmacy clients? Evidence from Kenya. Manuscript under review.
} 
Most (57\%) women purchasing EC reported having infrequent sexual intercourse or sexual intercourse on an irregular basis. Nearly half $(48 \%)$ of the respondents agreed that they might be at risk of getting HIV. Three-quarters $(74 \%)$ indicated that it would be a "big problem" if they found out that they were pregnant, but only $38 \%$ reported using a modern method of contraception (condom, injectable, oral contraceptive pill, IUD, Norplant, or sterilization - data not shown).

\section{Repeat use}

Respondents were asked a series of questions regarding recent EC use. Questions included the number of times they have used EC in the past six months, frequency of use of EC in relation to sexual activity, and time since last purchase of EC. The categorization of "repeat use" is based on the last question, and is defined as a client who has bought EC at least once previously in the past one month.

Under this definition, data indicate that a majority (58\%) of surveyed women purchased EC two or more times per month. The bulk of these purchasers (74\%) stated that they used EC as their only method during their last act of sex, nearly as many $(70 \%)$ thought that EC was more convenient than other methods, and almost half preferred EC over longer-term methods such as daily contraceptive pills or injectables.

While repeat use of EC may be a conscious decision, it is not necessarily an informed one. The data also demonstrates that women who repeatedly used EC have greater misperceptions about the method's mechanism of action and efficacy. Nearly 60 percent believed that EC is universally effective, and many harbored fears of infertility and concerns over abortion. Overconfidence in EC's efficacy is likely to be one factor underpinning repeat use, with the benefits of convenience in the shortterm outweighing perceived long-term RH costs.

\section{Intervention study: Towards a strategy for bridging}

The client intercept study demonstrated that pharmacy clients required more information on EC, and had the potential to be "bridged" to other RH services. It was not clear, however, how such activities could be integrated into the private sector. First, from a public health perspective, private pharmacies lack the incentives to provide additional services to EC clients, such as counseling or referrals for ongoing contraceptive use and STIs/HIV prevention, a concept referred to as "bridging". This could be attributed to the nature of training for pharmacists (which may not include the provision of public health information and services) as well as to the fact that interactions with clients at pharmacies are mostly with frontline staff some of whom lack formal training. ${ }^{10}$ Second, pharmacy providers are often faced

\footnotetext{
10 Program for Appropriate Technology in Health (PATH). 2004. "Increasing access to reproductive health services through pharmacists" Outlook 21(2). Seattle: PATH.
} 
with the challenge of balancing operations as a business establishment and performing the role of health service providers. ${ }^{11}$

Being the preferred sources of EC, the challenge is how to effectively enhance the capacity of private pharmacy providers to offer additional RH services to EC clients. One strategy which has been found to be effective in the short-term is the provision of on-the-job training. ${ }^{12}$ In the long-term, however, this strategy is ultimately unsustainable due to its high resource requirements and the regularity of staff turnover within pharmacies.

From October to December 2008, the Population Council tested the feasibility of using a minimally-invasive strategy to enhance the capacity of private pharmacy providers to offer counseling and referral for regular FP and other RH services to EC users. It aimed to limit repeat use by "bridging" current users to other RH services, including VCT and longer-term FP. ${ }^{13}$

\section{The intervention}

The study was conducted in 20 Nairobi pharmacies which were randomly divided into intervention and comparison groups. It included three components:

a) Detailing the providers (pharmacists and pharmacy assistants) on the appropriate use of EC and how best to dispense it to clients. The updates were done by a research assistant with prior experience promoting pharmaceutical products among health care providers (detailer). Such updates included providing information on the need to discourage repeat use, encourage the use of regular FP methods among repeat users, and refer EC clients for STI/HIV testing and counseling. Each pharmacy was visited once every week over a two- month period by the research assistant for the updates.

b) Ensuring the availability of PSI's IEC materials (brochures and posters) on EC use and provision to the pharmacies.

c) Provision of "cheat sheets" to pharmacies in the intervention group (Figure 2). The cheat sheets were small laminated fliers which were to be placed behind the counters, and intended to be easily recognizable by providers and EC clients. They contained three simple messages on EC: EC works within 5 days of unprotected sex; other methods of FP are more effective in preventing pregnancy; and EC pills do not protect against HIV and STIs. It was expected that the messages would discourage repeat use of EC and encourage bridging by

11 Skibiak, J.P., M.C. Moyo, Y. Ahmed. 2001. Testing alternative channels for providing emergency contraception to young women. Nairobi: Population Council.

12 Program for Appropriate Technology in Health (PATH). 2004. "Increasing access to reproductive health services through pharmacists" Outlook 21(2). Seattle: PATH.

${ }^{13}$ Obare F, Keesbury J, Liambila W. 2009. Bridging users of emergency contraceptives to other family planning and reproductive health services through private sector pharmacies in Nairobi, Kenya. Population Council: Nairobi. 
reminding providers and users alike that the need for EC is just a first step in a continuum of services which include counseling and referrals for regular FP and STI/HIV services.

Figure 2: 'Cheat' sheets with the key messages on EC (English and Kiswahili versions)

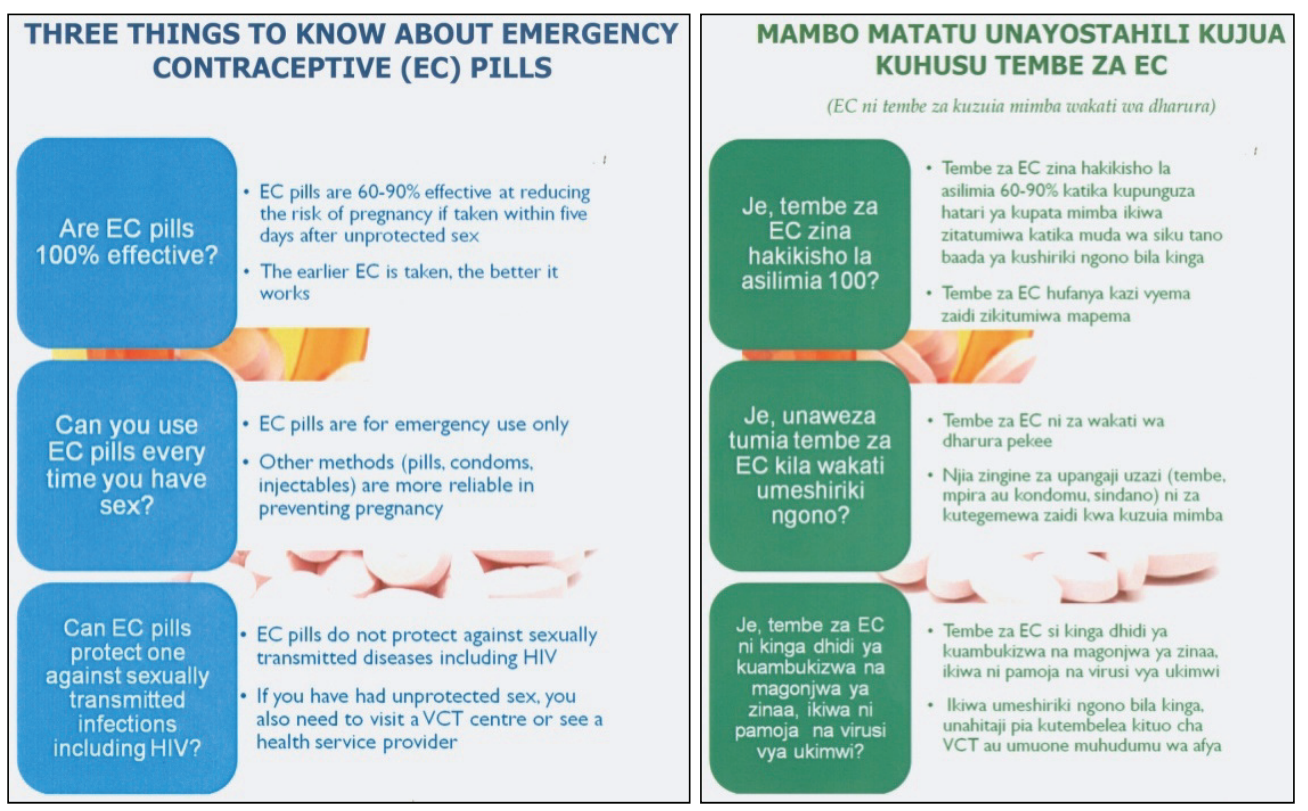

\section{Evaluation methodology}

Mystery clients (MCs) posed as potential or actual users of EC and acted as "real" clients. MCs were single adult women between the ages of 18-35 years. They presented to the providers with two scenarios as "experienced" and "inexperienced" EC users. They then observed the provider's ability to respond to the need for EC as a FP method as well as to other special needs within the broader RH context such as the provider's advice on HIV and other sexually transmitted infections (STIs). In addition to MC visits, focus group discussions were conducted with the detailer and pharmacists/pharmacy assistants at the end of the study to obtain information on their experiences with the various intervention strategies employed during the implementation phase.

\section{Barriers to access}

MCs were provided with EC pills in $82 \%$ of the visits to pharmacies. Purchase statistics further show that Postinor-2 and ECee2 were the only available brands, with the former comprising $97 \%$ of the purchased products and costing between 100 and 200 Kenya Shillings (USD \$1.30-2.60), depending on the pharmacy.

The main reasons for non-provision of EC were that: 1) the pharmacists insisted on doctors' prescriptions before they could dispense EC; and 2) the pills were out of stock at the time of the visit. EC has had over-the-counter status in Kenya since the 
late 1990s, and it is likely that pharmacists used such reasons to restrict access when they felt uncomfortable providing EC. These reasons are illustrated by the following excerpts from qualitative accounts:

I approached this lady at the counter, I couldn't tell her profession, and as I explained my situation, that I had sex and wanted some help to prevent unwanted pregnancy, she told me that they don't sell those drugs without a doctor's prescription. So there was no way she could help me. (MC No. RA06; Pharmacy No. WE23)

The man who attended to me didn't cooperate. After giving my story, he told me to go see a doctor who would give me a prescription. Then I take the prescription to him. (MC No. RA10; Pharmacy No. WE16)

I went to the chemist and found this man standing at the counter. I approached him and told him that I had unprotected sex last night and I have been advised by a friend that there are pills I could take to prevent conception. He told me to go and get all the information about EC before contemplating using the pills. I insisted that he tells me about the EC pills but he told me that they were out of stock because he had just sold the last packet. (MC No. RA10; Pharmacy No. KI77)

The lady attendant seemed to know about ECs ... On asking for P-2 [Postinor 2], the lady responded by saying that they had the medication but it got finished. But they would have them by the following day. (MC No. RA06; Pharmacy No. MA75) ${ }^{14}$

At both baseline and endline, MCs who presented as "experienced" clients were significantly less likely to be counseled then their "inexperienced" counterparts (Table 6). This may help explain the findings of the client intercept study, where repeat users demonstrated low levels of knowledge on the basics of EC.

\footnotetext{
${ }^{14}$ Obare F, Keesbury J, Liambila W. 2009: The provision of emergency contraceptives in private sector pharmacies in urban Kenya: Experiences of mystery clients. Forthcoming, African Journal of Reproductive Health.
} 
Table 6: Counseling on EC provided to MCs, experienced vs. inexperienced client scenarios

\begin{tabular}{|l|c|c|}
\hline & $\begin{array}{c}\text { MC presented as } \\
\text { experienced client }\end{array}$ & $\begin{array}{c}\text { MC presented as } \\
\text { inexperienced client }\end{array}$ \\
\hline Counseling provided on EC, baseline & 25 & $69^{* *}$ \\
\hline Counseling provided on EC, end line & 17 & $73^{* *}$ \\
\hline Counseling provided on EC, all visits & 20 & $71^{* *}$ \\
\hline
\end{tabular}

** $p<0.01$

\section{Increased information provision on EC}

For those who received EC, the intervention appears to have increased the type and amount of information provided. Significant changes were registered at endline with regard to information provided on "when to use EC" and "what EC does".

\section{Increased bridging to other RH services}

Bridging EC users to other RH services entails counseling and/or referrals for other contraceptive methods and HIV/AIDS/STI services (such as counseling and testing). The proportions of $\mathrm{MC}$ visits during which the provider offered other FP services and talked about HIV/STIs are higher in the intervention than control pharmacies at endline (Figure 3). There are also increases in these proportions in the intervention pharmacies between the baseline and endline.

Figure 3: Distribution of MC visits by types of EC counseling provided in the intervention pharmacies at baseline and endline

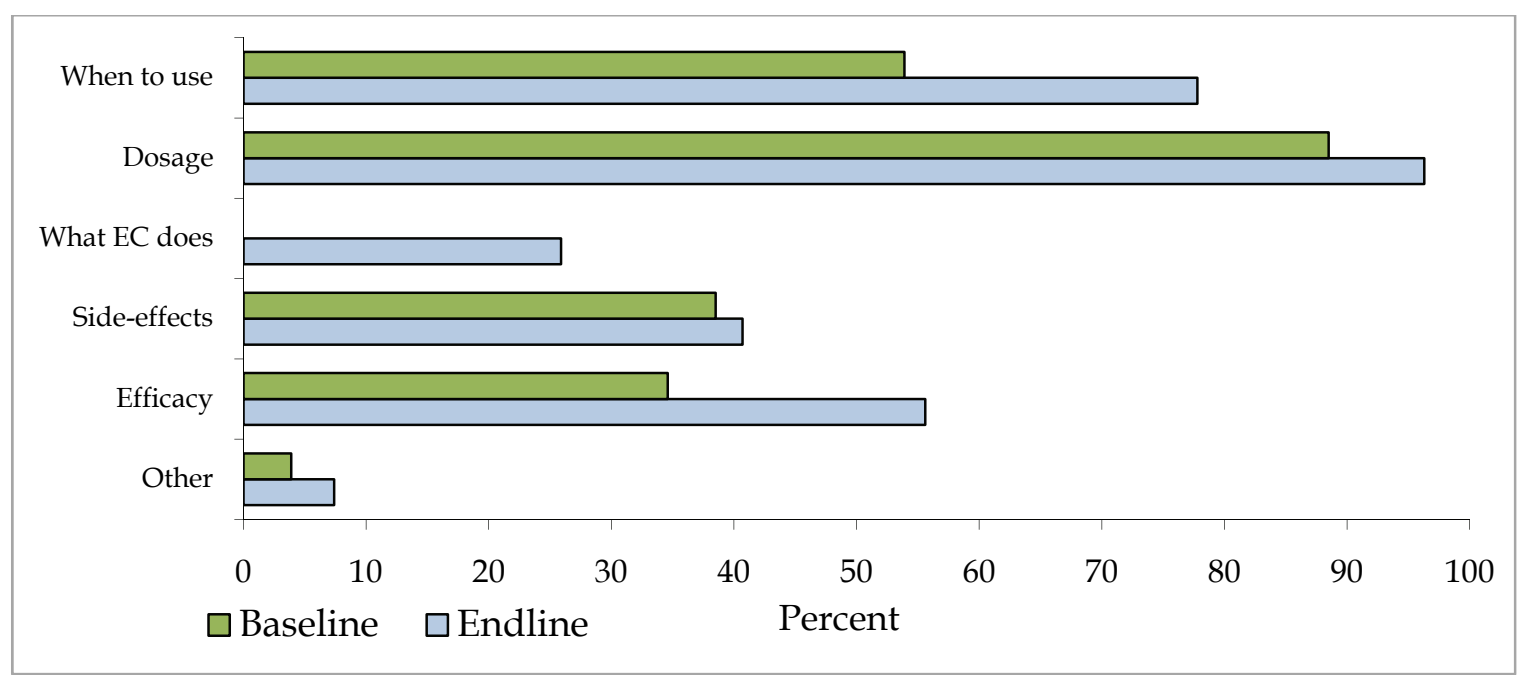


The proportion of visits during which the provider recommended regular FP services or referred the MC to clinic or hospital for another contraceptive method increased in the intervention pharmacies between baseline and endline (Figure 4). The same applies to the proportion of visits during which the provider recommended abstinence or referred the $\mathrm{MC}$ to a voluntary counseling and testing (VCT) center. Although these increases are in the expected direction, they are not statistically significant.

Figure 4: Distribution of MC visits by other specific FP services provided in the intervention pharmacies at baseline and endline

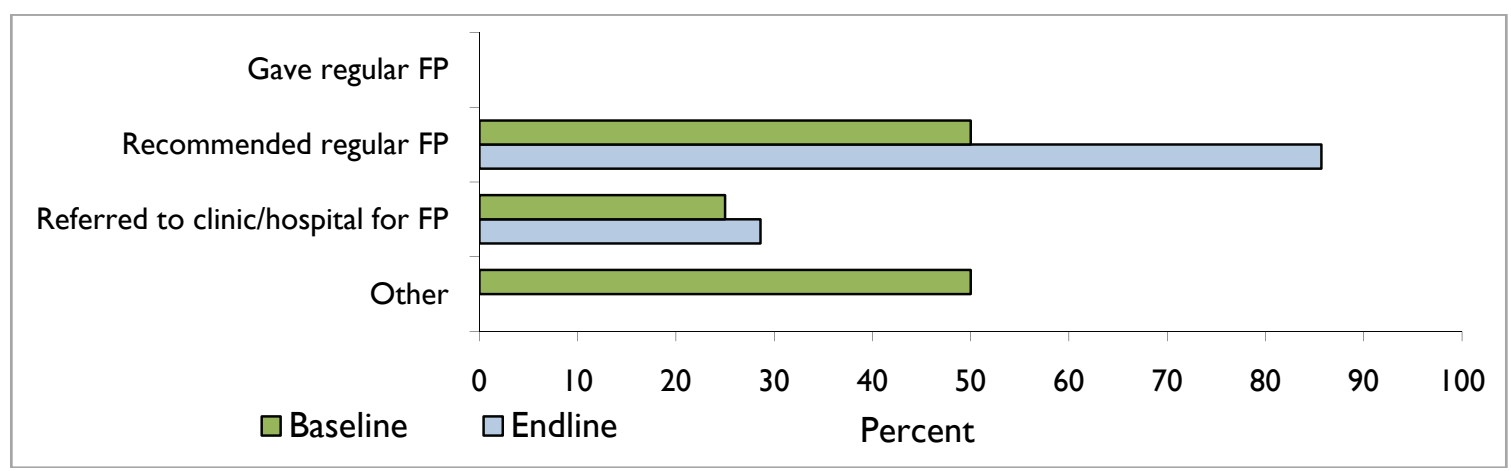

\section{Utilization of Results}

These studies provide important new insights into the nature of EC use in Kenya and strategies for engaging the private sector to improve EC provision. These results will be disseminated widely in Kenya to encourage the private sector to adopt such strategies as a response to concerns over "misuse" of EC. With the support of PSI, national disseminations will be undertaken with the PSK and the broader RH community.

These findings are also important for other countries in Africa where EC provision is increasingly dominated by the private sector. With support from the Council's ECafrique network, the Kenyan experience will be shared within the region through publications and conference presentations. An article on baseline results is forthcoming in the African Journal of Reproductive Health, and study updates have been provided through the ECafrique newsletter and listserv. In October 2009, results were presented in Nairobi at the 8th International Conference on Urban Health: Meeting Urban Health Needs through Innovative Research, Policies and Interventions.

Internationally, these results have also contributed to the emerging dialogue on private sector provision of RH services. In early June 2009, the Council was invited by Ipas to present these results at a meeting on expanding access to other RH drugs through pharmacies, chemist shops and medicine sellers convened in North Carolina. Findings of the client intercept were presented at the 2008 International Consortium on EC meeting, and results of the intervention study were shared at the 2009 annual meeting. 


\section{COMPONENT 3: STRENGTHENING EC INTHE PUBLIC SECTOR}

As noted above, $\mathrm{MOH}$ guidelines and service delivery strategies have included EC for over a decade. In recent years, however, limited funding for FP and competing demands within the health sector have diverted attention from EC as an element of FP. The MOH's increased emphasis on post-rape care helped to reinvigorate EC services, but also skewed service provision and training strategies.

An important component of this initiative, therefore, was to strengthen EC services in the public sector, within the contexts of family planning services and of post-rape care.

\section{Generating political will}

At the outset of the initiative, the $\mathrm{MOH}$ was unconvinced of the need to strengthen public sector EC services. As a leader on EC in Africa, the $\mathrm{MOH}$ had already incorporated it into its family planning and post-rape care programs, and had recently ordered a substantial consignment of 700,000 units of Postinor-2.

Nonetheless, other stakeholders expressed concern that family planning providers were inadequately trained on EC, harbored biases that served as barriers to access and suffered from irregular supply at the district and facility levels. The Council employed an evidence-based advocacy strategy to inform and support the MOH's EC activities.

\section{7 assessment results}

To better understand the current state of EC provision in Kenya, the MOH requested that the Population Council undertake an assessment of EC services across the country. With support from UNFPA, this assessment was expanded to include data on female condoms and intra-uterine devices. ${ }^{15}$ Data were collected from 199 government health care facilities located in eight districts in five provinces. Two primary sources were used in the analysis: a knowledge, attitudes and practices (KAP) survey administered among 524 health care providers; and a review of all EC, FC or IUD clients included in each facility's family planning (FP) register over an 18month period.

Results demonstrated that providers had limited knowledge and experience with EC. Key findings included:

- Only 56\% of the 524 providers surveyed in 2007 reported having been trained to provide $\mathrm{EC}$;

\footnotetext{
${ }^{15}$ Keesbury, Jill,Benter Owino, and Spike Bradford. 2007. Emergency contraception, female condoms, and IUDs in Kenya's public sector: Findings from a national diagnostic assessment. Nairobi: Population Council.
} 
- Less than $5 \%$ correctly identified the timeframe for EC use included in the 2005 revision of the National FP Guidelines, and less than half knew that it was legal in Kenya;

- Half (51\%) of all providers believed that access to EC pills encouraged promiscuity among young women;

- Most of the EC recorded in facility registers (93\%) was given to rape survivors.

\section{MOH leadership in EC mainstreaming}

In August 2007, these findings were presented to the $\mathrm{MOH}$ and key partners at a data interpretation workshop which served as a turning point in the EC initiative. At its conclusion, a formerly reticent $\mathrm{MOH}$ official noted that " $[E C]$ is a necessary service especially for adolescents and young people...we cannot ignore EC any longer."

Since then, the $\mathrm{MOH}$ has shown leadership in strengthening EC services in the public sector. It has publically expressed support for strengthening EC provision, especially for youth, and has worked collaboratively with the Population Council to do so. The Council was asked to prepare information on EC for 2008 World Contraception Day celebration. The issue of EC "misuse" has been addressed by senior leadership at the $\mathrm{MOH}$, which has recognized the need for greater awarenessraising efforts around EC.

The MOH also collaborated with the Council, PSI and the ICEC to correct misinformation on Kenya's EC program published by the BBC. In July 2009, the BBC published an article that critiqued PSI's media campaign, contending that increased knowledge of EC was likely to undermine the country's HIV prevention activities ${ }^{16}$. In response, $\mathrm{MOH}$ officials talked to the media and subsequently released a press statement that underscored the government's commitment to ensuring access to EC, especially among youth.

Lessons learned from this initiative were also incorporated into the 2010 revision of the National FP Guidelines, which includes expanded guidance of EC counseling and "bridging" to other methods. Importantly, these guidelines indicate that all levels of service providers, including community health workers and communitybased distributors, can provide EC. This creates the opportunity for broader provision of EC at the community-level, especially in rural areas where access is currently limited.

\footnotetext{
${ }^{16}$ Mawathe A. July 14, 2009. Kenya Concern over Pill Popping. http://news.bbc.co.uk/2/hi/africa/8145418.stm
} 


\section{In-service training}

As indicated in the 2007 assessment, limited provider training presented a key barrier to providing quality EC services in the public sector. As a result, the Council collaborated with the $\mathrm{MOH}$ and its other partners to strengthen in-service training on EC.

\section{Materials development}

To support training efforts, the Council worked with the $\mathrm{MOH}$ to develop a set of EC training materials. Drawing on the National FP guidelines, a comprehensive PowerPoint presentation on EC was developed for trainers. A companion booklet, the Health Care Providers Quick Reference Guide, was also published as part of a strategy intended to enable as many health care providers as possible to have access to user-friendly and updated materials on emergency contraception.

In addition to use in the trainings described below, the booklet was also distributed by the $\mathrm{MOH}$ as part of its 2009 World Population Day activities, and was used as source material for the 2010 update of the National FP Guidelines.

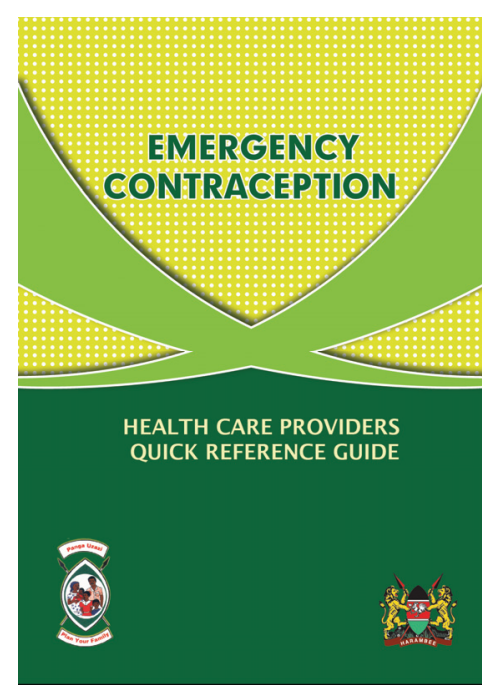

Government officials in Zambia and Uganda have also requested copies of this booklet for use in their countries.

\section{Trainings}

Recognizing that national trainings of health care providers were beyond the scope of this initiative, the Council looked for strategies to integrate EC into existing training activities. This approach was intended to ensure the sustainability of training efforts, limit costs and address EC within the context of integrated RH and FP services.

Under this approach, the Council enlisted the cooperation of other NGOs charged with providing FP/RH training across the country. These NGOs funded under USAID's APHIA II health services program, included partners such as PATH, JHPIEGO, Family Health International, Pathfinder International, Engender health and Intrahealth. The Council provided a one-day update session on EC to relevant staff from each partner institution and provided them with materials on EC. Following the update session, partners were expected to ensure that EC was adequately addressed in their training programs. After this meeting, partner representatives organized for the training of health providers (deployed at dispensaries, health centres and hospitals) in all provinces. Through this strategy, a total of 1906 providers were trained on EC in 2007 and 2008. 
In addition to supporting the APHIA II partners, the MOH requested that the Council support provincial-level Contraceptive Technology Updates (CTUs). The purpose of the training was to address the gap in coverage so as to increase the proportion of facilities with trained staff -since APHIAII teams do not cover all the facilities in the provinces.

As indicated in Table 7, a total of 2,036 providers were trained on EC over the first two years of the initiative. Of these, 56 were trainers of trainers (TOTs) who were expected to replicate the training at district level.

Table 7: Number of in-service health providers trained on EC in the context of RH/ HIV integration

\begin{tabular}{|l|c|c|}
\hline \multirow{2}{*}{ Province } & \multicolumn{2}{|c|}{ No. of Health Providers Trained in EC/FP/RH } \\
\cline { 2 - 3 } & $\mathbf{2 0 0 7}$ & $\mathbf{2 0 0 8}$ \\
\hline Western & - & 125 \\
\hline Eastern & 419 & 662 \\
\hline Nyanza & 52 & 55 \\
\hline Coast & - & 151 \\
\hline Nairobi & - & 103 \\
\hline Central & 63 & 108 \\
\hline North Eastern & - & 74 \\
\hline Rift Valley & - & 224 \\
\hline Totals & 534 & 1502 \\
\hline
\end{tabular}

\section{Pre-service training}

Although EC was adequately integrated into the National FP Guidelines, it had not yet been included into the curricula of the major medical training institutions. To ensure long-term sustainability and reduce the need for costly pre-service training activities, the Council also focused on incorporating EC into key training curricula.

\section{Kenya Medical Training College meeting}

In December 2008, the Kenya Medical Training College (KMTC) convened a one-day meeting to identify new areas to be added to the existing curriculum and the topics that needed to be reviewed or revised in the family planning module for registered nurses and clinical officers. In the meeting, EC was identified as one of the priority topics to be incorporated in the current RH/FP curriculum for nurses and clinical officers. 


\section{Nursing Council of Kenya curriculum revision}

Based on the consensus of the KMTC meeting, the Nursing Council of Kenya (NCK) included EC in the 2009 revision of the National Registered Nursing syllabus and procedure manual for nurses. As a national regulatory body, the NCK is mandated to ensure quality training for nurses through the periodic revision of a national training file, syllabus and procedure manual. Incorporation of EC into the syllabus ensures that EC is included in all professional education and examinations.

As articulated by the NCK, EC was considered an emerging issue in reproductive health that is of immense public health importance. The sub-topics covered under emergency contraception in the syllabus are: definition, indications, types, modes of action, dosage guidelines, side effects, counseling of clients, importance of bridging EC users to other RH and HIV/AIDS/STI services, and common questions and concerns from clients that health providers need to know.

\section{Ensuring stock sustainability}

The MOH, with support of UNFPA, has made notable efforts to maintain consistent stocks of EC. Since 2005, the MOH has obtained 1,100,000 units of EC, and has committed to purchasing another 5,875,000 Units (expected June 2010) with its own funds. Despite these efforts, the $\mathrm{MOH}$ has experienced challenges in meeting demand for the method. As Figure 5 illustrates, by the end of July 2009 only 0.3 months of EC stock was remaining in KEMSA stores, and procurement for an additional 10.3 months supply was pending. Unfortunately, this is below the minimum recommended stock level of 12 months, and requirements are expected to increase along with awareness.

Figure 5: Short term contraceptive commodities stock status, July 2009

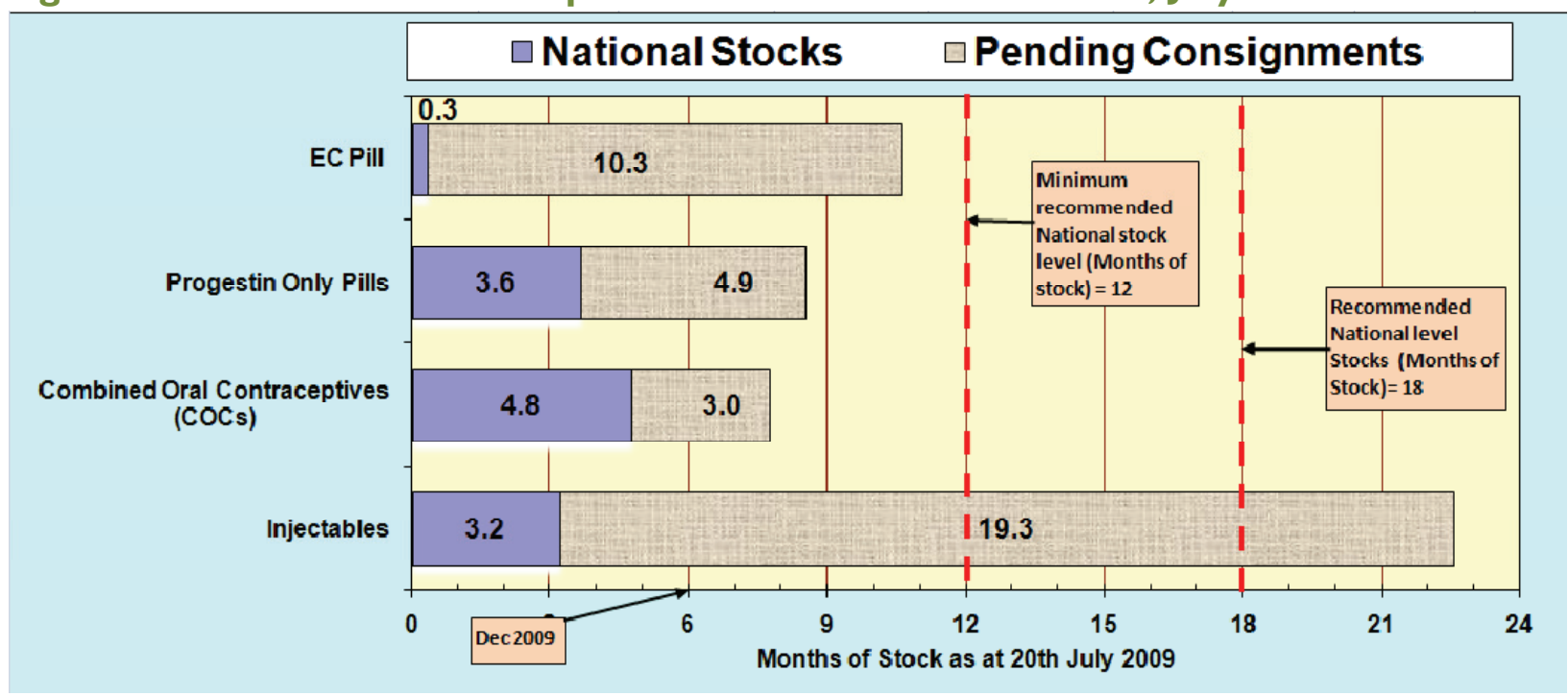

Source: FP Commodity Stock Status June 2009 - MSH data from LMU, DRH, KEMSA, UNFPA, USAID and PSI 


\section{Policy and procedure changes}

The Initiative has been successful in ensuring that EC is integrated into the documents that underpin contraceptive security. In 2008, a column for EC was added to the revised FP register, which helps to ensure that EC utilization is properly recorded and captured in facility-level stock re-ordering. An example of the current register is shown in Appendix 1.

EC is also included in the country's national Contraceptive Security Strategy, which is intended to limit stock-outs of essential family planning commodities.

\section{Evaluation of training outcomes}

Overall, in-service training constituted the most extensive element of the public sector strengthening program and had the potential to demonstrate the most impact within the life of the initiative. As a result, the evaluation of this component consisted of national surveys to assess the outcome of training efforts on providers' knowledge, attitudes and practices (KAP) toward EC.

\section{Methods}

In May 2009, providers in Rift Valley and Central Provinces participated in a KAP survey on FP and EC. ${ }^{17}$ These providers were asked the same set of questions as those who participated in the 2007 assessment, although due to differences in the sampling methodology, the two data sets are not directly comparable. Variations in the penetration of training efforts, especially those conducted by the APHIA II partners, rendered replication of the 2007 sampling strategy ineffective in capturing the impact of the trainings. Instead, a more focused evaluation strategy was adopted that compared sites known to have received CTU trainings with those that did not.

A total of 30 health facilities (15 in each province) matched by level ( 7 hospitals, 7 health centers and 1 dispensary from each site) were included in the study. In each of the selected facilities, all cadres of health care providers who are likely to provide EC and other family planning (FP) services (obstetricians and gynecologists, clinical officers, nurses, and midwives) were eligible to respond to a self-administered questionnaire. A total of 74 providers from CTU and 73 from non-CTU facilities participated in the study. The questionnaires solicited information on the providers' background characteristics, knowledge of EC, prior experiences with dispensing EC, and perceptions about its efficacy and side-effects. Providers who had ever dispensed EC were also asked whether they offered additional reproductive health (RH) services to EC clients, such as post-exposure prophylaxis (PEP) for HIV, counseling or referral for HIV/STIs, and referrals to police, higher-level facility, or abortion services.

\footnotetext{
${ }^{17}$ Obare F, Keesbury J, Liambila W. 2009. Final assessment of the impact of contraceptive technology updates on provider knowledge, attitudes and practices towards emergency contraception in Kenya. Draft report. Population Council: Nairobi.
} 


\section{Provider characteristics}

As demonstrated in Table 8, the characteristics of providers in the CTU and nonCTU sites were largely similar, with the exception of significant differences in sex, proportion located at a district hospital, and the proportions of doctors. In the 2007 assessment, more providers were located at health centers and dispensaries, and were more likely to work in the out-patient department, maternal and child health or family planning clinics.

Table 8: Distribution of respondents by background characteristics

\begin{tabular}{|c|c|c|c|c|}
\hline Characteristics & $\begin{array}{l}2007 \\
\text { assessment } \\
(n=524), \%\end{array}$ & $\begin{array}{l}\text { CTU site, } \\
2009 \\
(\mathbf{N}=74), \%\end{array}$ & $\begin{array}{l}\text { Non-CTU site, } \\
2009(\mathrm{~N}=73) \\
\%\end{array}$ & $\begin{array}{l}\text { All } 2009 \\
\text { sites } \\
(\mathrm{N}=147), \%\end{array}$ \\
\hline Mean age (years) & 37 & 37 & $37^{\mathrm{ns}}$ & 37 \\
\hline Percent female & 79 & 87 & $70^{*}$ & 78 \\
\hline \multicolumn{5}{|l|}{ Level of facility } \\
\hline District hospital & 16 & 79 & $75^{*}$ & 75 \\
\hline Health center & 32 & 18 & $23^{\mathrm{ns}}$ & 20 \\
\hline Dispensary & 52 & $\mathrm{I}$ & $3^{\mathrm{ns}}$ & 2.0 \\
\hline Missing & -- & 4 & $0^{\text {ns }}$ & $\mathrm{I}$ \\
\hline \multicolumn{5}{|l|}{ Professional qualification } \\
\hline Doctor & 2 & 5 & $0^{*}$ & 3 \\
\hline Clinical officer & 10 & 13 & $16^{\mathrm{ns}}$ & 15 \\
\hline Enrolled nurse/midwife & 12 & 8 & $1 I^{\text {ns }}$ & 9.5 \\
\hline $\begin{array}{l}\text { Reg. or enrolled community } \\
\text { health nurse }\end{array}$ & 61 & 68 & $70^{\text {ns }}$ & 69 \\
\hline Other/missing & -- & 5 & $3^{\text {ns }}$ & 4 \\
\hline \multicolumn{5}{|l|}{ Primary department ${ }^{\text {a }}$} \\
\hline Family planning & 42 & 27 & $27^{\mathrm{ns}}$ & 27 \\
\hline Maternal/child health clinic & 54 & 10 & $18^{\mathrm{ns}}$ & 14 \\
\hline Out-patient & 44 & 14 & $21^{\mathrm{ns}}$ & 17 \\
\hline Obstetrics/gynecology & 15 & 8 & $10^{\mathrm{ns}}$ & 9 \\
\hline Comprehensive care clinic & 19 & 19 & $8^{\mathrm{ns}}$ & 14 \\
\hline Ever trained to provide $\mathrm{EC}^{\mathrm{b}}$ & 56 & 58 & $39^{*}$ & 49 \\
\hline $\begin{array}{l}\text { Trained within past two } \\
\text { years }\end{array}$ & 49 & 54 & 32 & 47 \\
\hline Type of EC trained to provide ${ }^{a}$ & & $(\mathrm{~N}=43)$ & $(\mathrm{N}=28)$ & $(N=7 I)$ \\
\hline IUCD & 16 & 11 & $21^{\mathrm{ns}}$ & 16 \\
\hline Postinor 2 & 92 & 91 & $82^{\mathrm{ns}}$ & 87 \\
\hline Pregnon & -- & 7.0 & $35^{* *}$ & 18 \\
\hline ECee2 & -- & 18 & $21^{\mathrm{ns}}$ & 19 \\
\hline Smart Lady & -- & 14 & $7^{\mathrm{ns}}$ & 11 \\
\hline Yuzpe method & 51 & 47 & $50^{\text {ns }}$ & 48 \\
\hline \multicolumn{5}{|c|}{$\begin{array}{l}\text { Notes: }{ }^{\text {a }} \text { Question allowed for multiple responses-- percentages do not therefore sum to } 100 \text {; }{ }^{\mathrm{b}} \mathrm{Among} \text { those } \\
\text { who had ever heard of EC; Differences between CTU and non-CTU sites are statistically significant at: }{ }^{* *} \mathrm{p}<0.0 \mathrm{I} \text {; } \\
{ }^{\mathrm{p}} \mathrm{p}<0.05 \text {; }{ }^{\text {ns}} \text { - not significant. }\end{array}$} \\
\hline
\end{tabular}


As expected, a significantly higher proportion of providers from the CTU facilities reported having been trained to provide EC (58\% vs. 39\%). While this finding is encouraging, it also highlights a shortcoming in the CTU program, which relies on TOTs to deliver cascade training. But, as the findings below suggest, the presence of such trained providers in a facility appears to increase the overall performance of all associated providers.

A higher proportion of providers from the CTU facilities reported having been trained within the last two years compared to their counterparts from the non-CTU facilities (54\% vs. $32 \%)$. This indicates that the training was conducted during the project period.

In 2007, training on EC was dominated either by Postinor-2 or the Yuzpe method. By 2009 , training began to reflect the diversity of products on the market, including Pregnon, ECee2 and Smart Lady. While more providers in the non-CTU sites were trained to provide Pregnon and ECee2, as indicated below, such instruction did not significantly improve provider attitudes or practices regarding EC provision, suggesting the content of these trainings differ significantly.

\section{Increased general knowledge of EC}

Overall, providers at the CTU sites demonstrated higher levels of general knowledge on EC (Figure 6). However, it is important to note that knowledge on certain aspects of EC, such as having ever heard of EC or knowing that it does not protect against HIV/ STIs, was almost universal in 2007. Such high levels in the general population are most likely attributable to the media attention given to EC in Kenya prior to the start of the initiative, while PSI's awareness creation campaign is likely to have also contributed to higher knowledge levels in 2009. The CTU training also appears to have improved provider knowledge in the participating sites.

\section{Figure 6: General knowledge of EC}

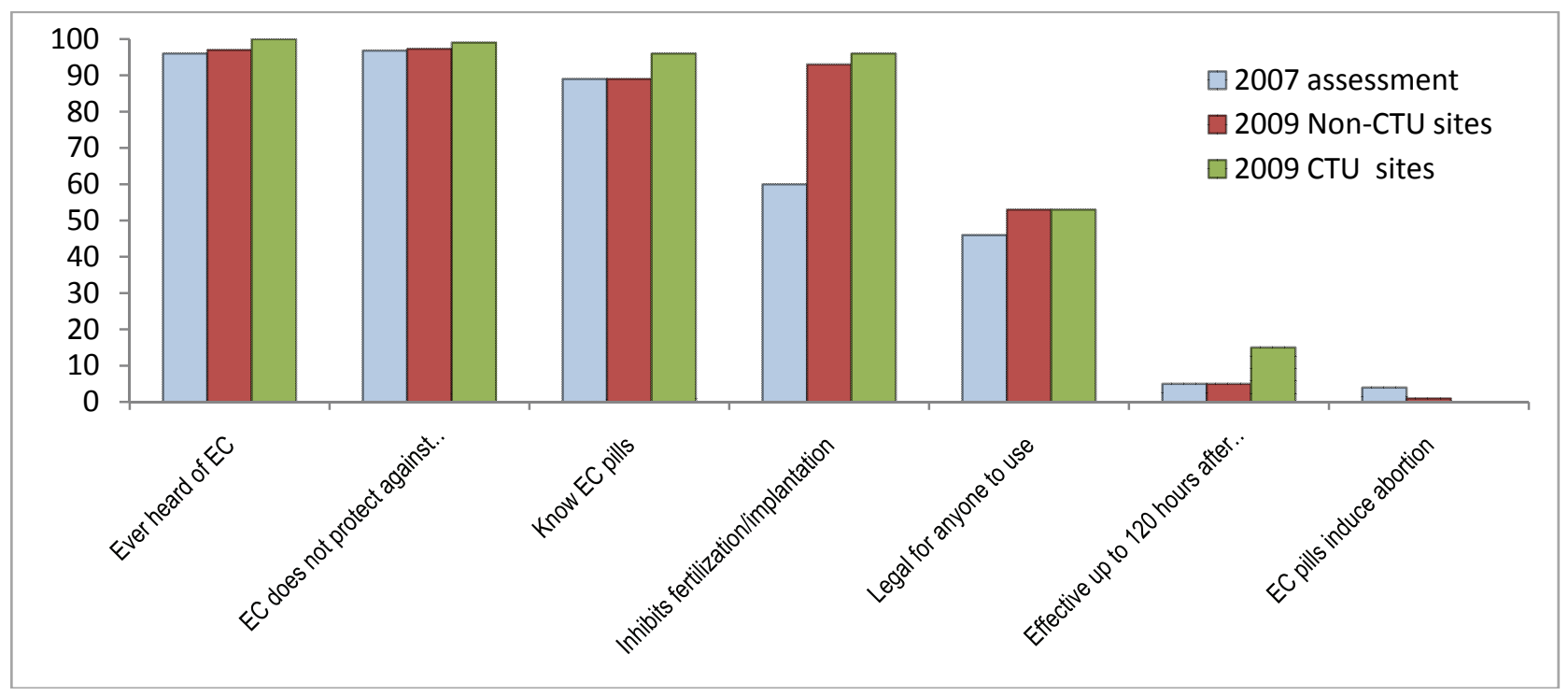


CTU training appears to have had the most impact on levels on knowledge regarding the existence of a dedicated product ("EC pills"), and the time period of under which it is used. Although CTU providers were more likely to know the 120 hour timeframe included in the National Family Planning guidelines, only $15 \%$ of these providers correctly identified this limitation. Notably, not one of the providers in the CTU sites agreed that EC could induce abortion.

\section{Increased knowledge of EC}

Formative research demonstrated that side-effects are an important concern for potential users, and inaccurate media reports have contributed to public misperceptions throughout the life of the initiative. Even more reliable sources, such as the BBC, have incorrectly asserted that "regular use of the emergency contraception may cause infertility and in some instances increase the risk of cancer."18

To overcome such barriers, CTU trainings placed an emphasis on ensuring that providers were aware of the correct side-effects of EC. As Figure 7demonstrates, providers in CTU sites were significantly more likely to state correct side effects, such as nausea and missed periods. They were also less likely than those in the nonCTU sites to identify incorrect side-effects such as ectopic pregnancy, infertility and deformed babies. Nonetheless, the data demonstrates that more efforts must be made to ensure that all providers are correctly informed on the side-effects of EC.

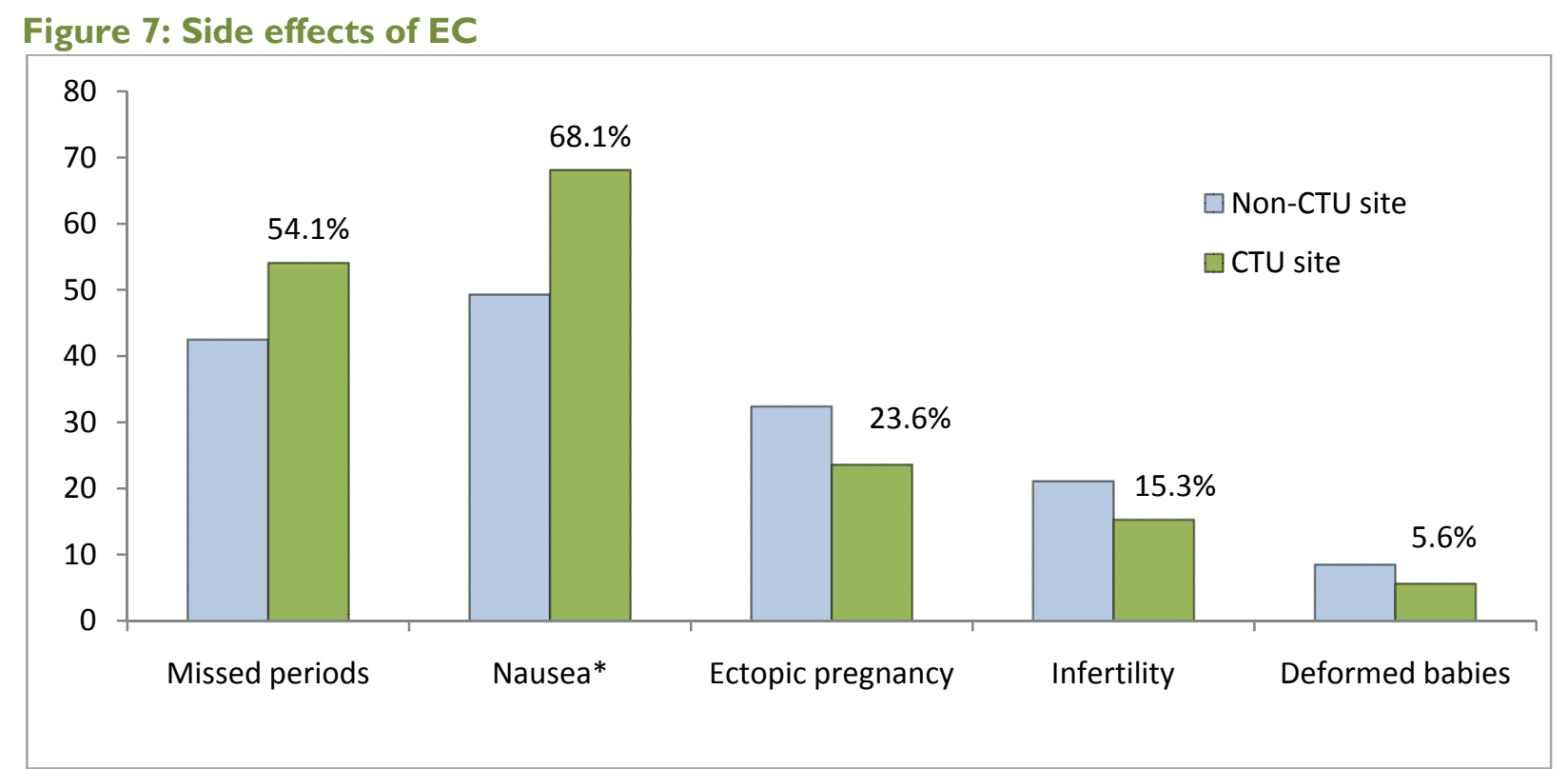

${ }^{*} \mathrm{p}<0.01$

Significant differences were also seen between the sites regarding the number of times providers believed EC should be taken in a month. The National FP guidelines state that EC is not to be used as a regular method of contraception, and authorities suggest that if it is taken more than once in a month, providers should recommend

${ }^{18}$ Mawathe A. July 14, 2009. Kenya Concern over Pill Popping. http://news.bbc.co.uk/2/hi/africa/8145418.stm 
alternate forms of contraception. Providers in the CTU sites were significantly more likely to be aware of this provision $(60 \%$ vs. $43 \%, p<0.05)$, suggesting that it was adequately stressed in training and then diffused throughout the facility. Similarly, fewer providers in the CTU sites were likely to believe that EC should be taken as often as needed (5.4\% vs. $14 \%)$. These findings have important implications for strategies to limit repeat use and "bridge" clients to other methods, both of which have been identified as priorities by the $\mathrm{MOH}$.

\section{Increased counseling and provision of EC}

Providers in the CTU sites were also significantly more likely to have provided EC to a client than their counterparts in facilities that did not benefit from similar training (Figure 8). Those in the CTU sites also were more likely to counsel their clients on EC, reflecting a comparatively high level of comfort with the method.

Figure 8: Counseling and provision of EC

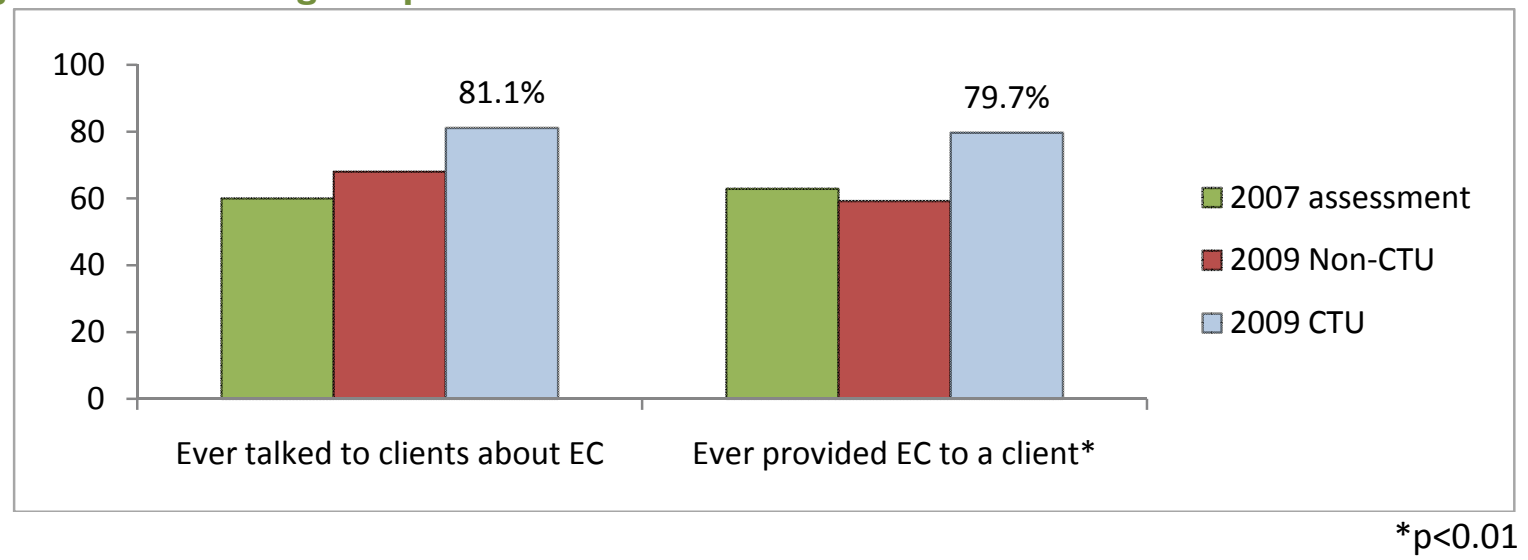

As Figure 9 indicates, overall, providers who were trained on EC were significantly more likely to offer additional information on the method their EC clients. While few differences were found between the CTU and non-CTU sites, when looking at all sites, trained providers performed much better than their non-trained counterparts. Although providers in CTU sites had overall higher levels of knowledge on EC, they were no more likely to communicate that information to their clients. Those who attended trainings on EC were significantly more likely to counsel their clients, suggesting that training in general (not a specific type) increases providers' ability to counsel on EC. 
Figure 9: Provision additional information on EC by training status (\%)

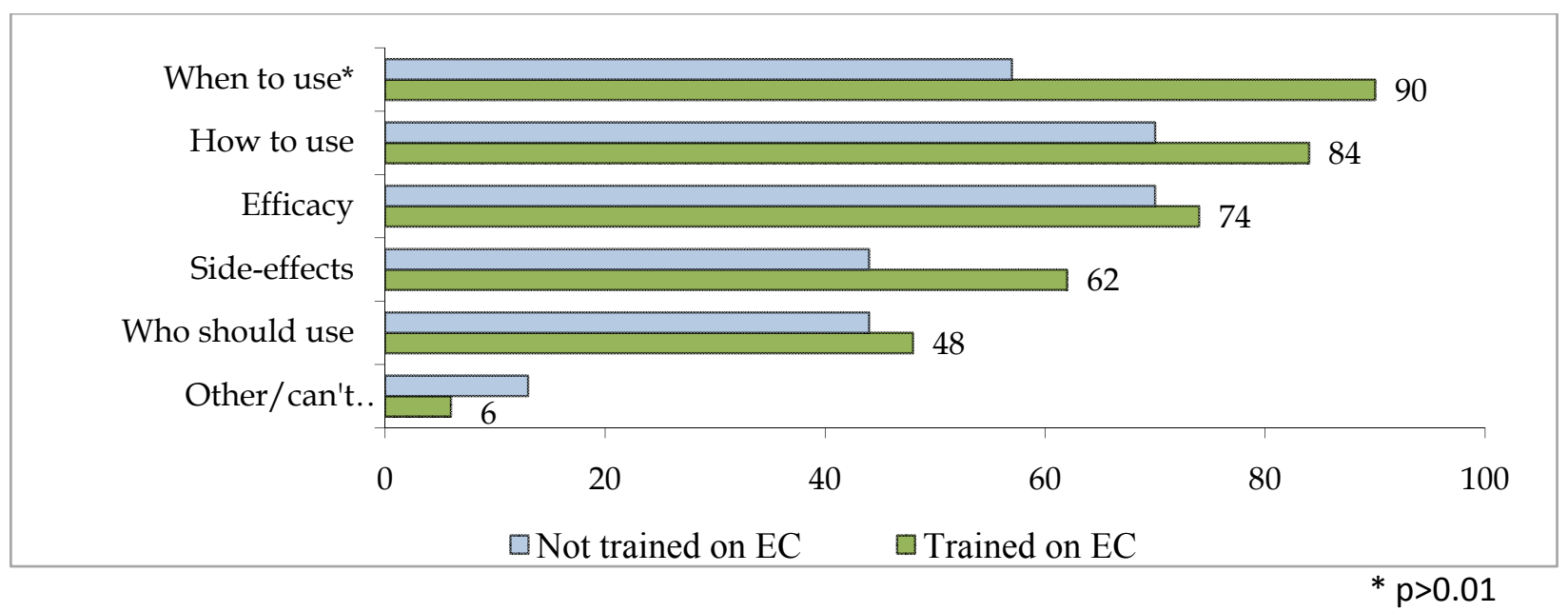

Improved "bridging" behaviors

Surprisingly, providers in CTU sites were no more likely to "bridge" EC users to other RH services, and in some cases were even less likely. This suggests that the CTU trainings did not adequately stress bridging issues, or that such information was not diffused throughout the participating facilities. However, when compared to the results of the 2007 assessment, notable improvements in bridging behaviors were realized (Figure 10).

Figure I 0: Bridging behaviors, 2007 vs. 2009 (\%)

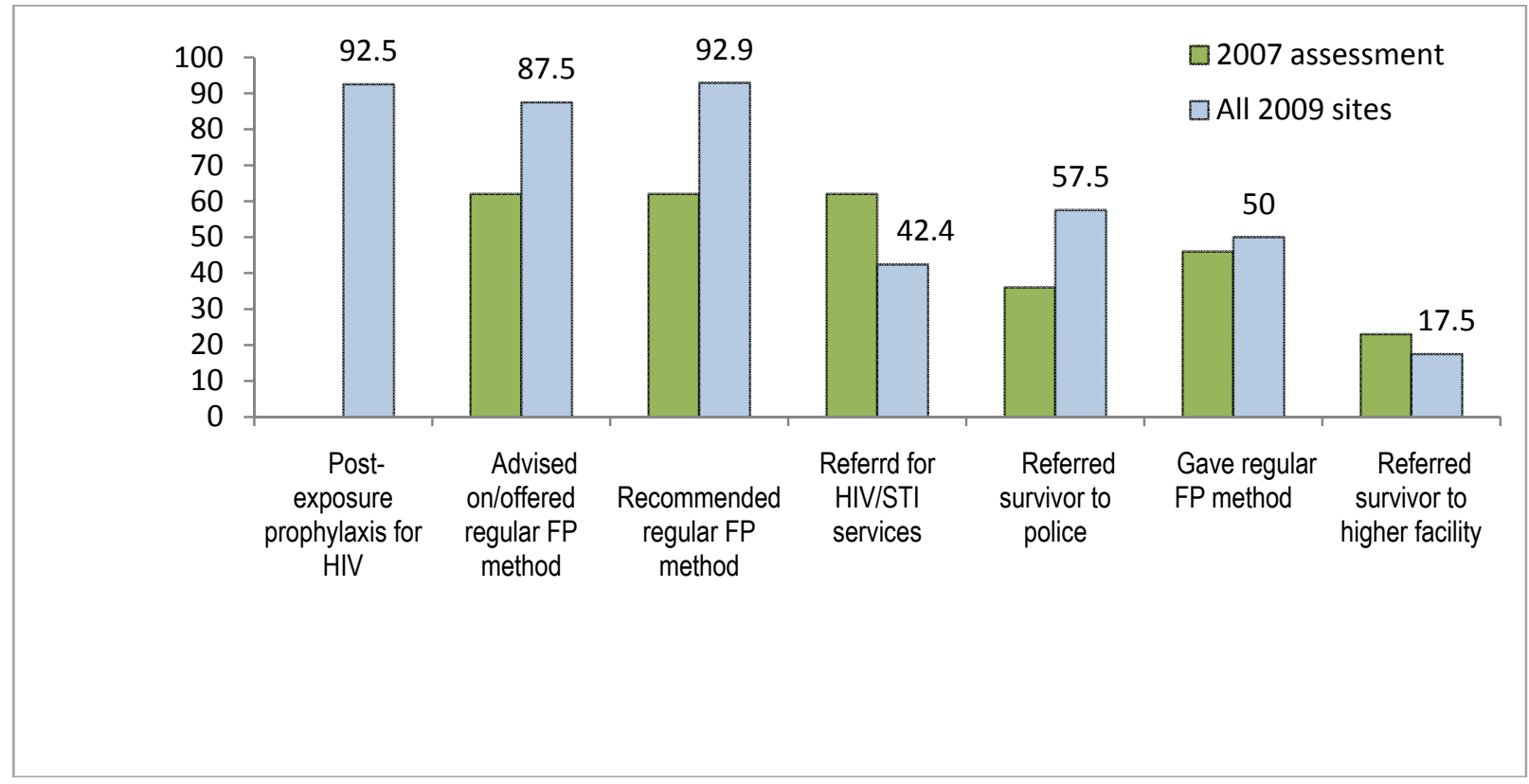

In 2009 , slightly more than two-fifths (42\%) of the providers whose last clients needed EC for FP reasons reported offering services or referral for VCT for HIV/STIs. The majority of the providers recommended condom use $(71 \%)$ or abstinence $(43 \%)$ while $29 \%$ referred the client to a VCT center. Again, providers who were trained in EC were more than twice as likely to offer services or referrals for VCT compared to those who are not trained ( $50 \%$ vs. $23 \%$; $<<0.05)$. 


\section{Improved attitudes toward EC use for adults, no change for adolescent use}

Providers in the CTU sites demonstrated more favorable attitudes toward EC use among adults (self and friends), although fears of misuse among adolescents remained relatively constant across the sites (Figure 11). The portion of providers agreeing that access to EC promotes promiscuity did not change from 2007 to 2008 (51\% vs. 53\%), reflecting continued discomfort with adolescent access to EC.

Figure I I: Attitudes toward EC, CTU vs. Non-CTU sites

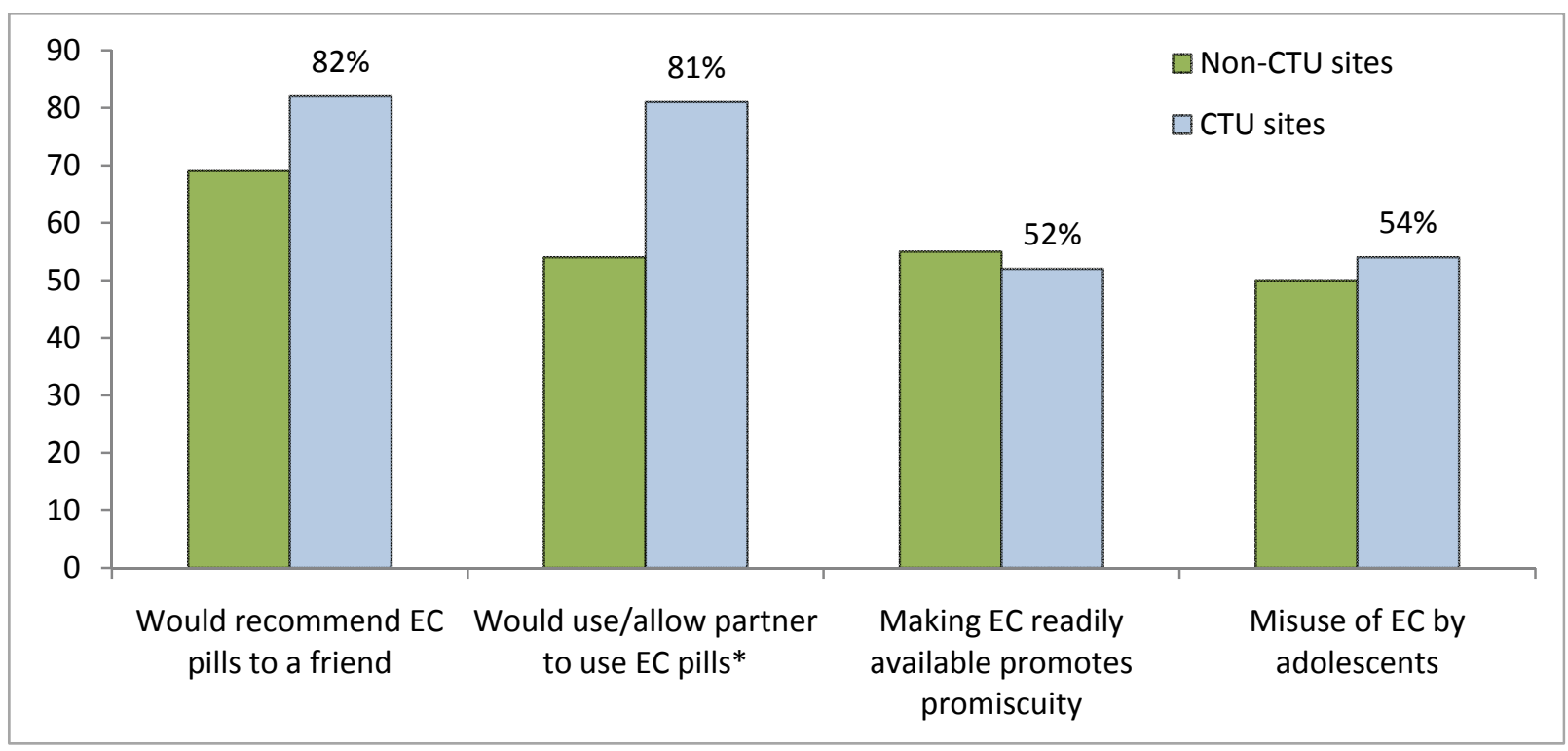

${ }^{*} \mathrm{p}<0.05$

These fears most likely reflect the discourse surrounding EC in the Kenyan media, which has associated EC with risky sexual behavior among adolescents. These results suggest that much more communication will be needed to overcome these biases toward EC use among young people.

\section{Rape survivors still constitute the largest proportion of EC clients}

The 2007 assessment demonstrated that the bulk of EC clients in the public sector were rape survivors. Following the dissemination of those results, the $\mathrm{MOH}$ renewed its commitment to increasing access to EC as an element of it FP services, especially for adolescents. Figure 12 demonstrates that the $\mathrm{MOH}$ has not yet been successful in repositioning EC as a FP method. 
Figure I2: Reasons for seeking EC, provider recall

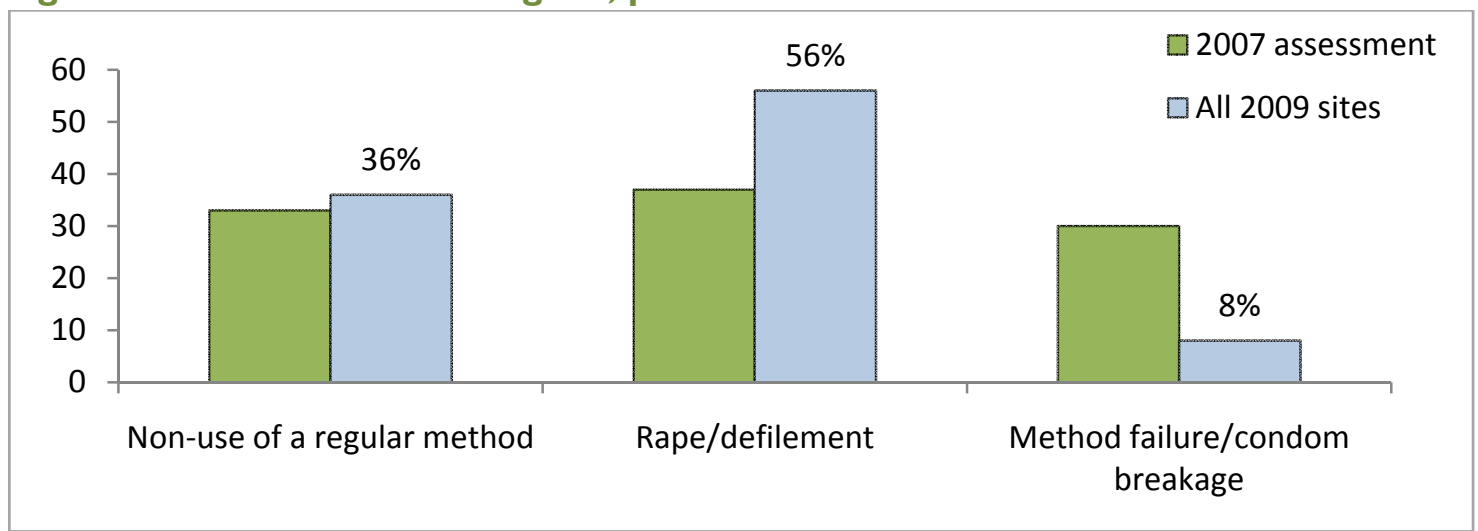

Providers also indicated that largest proportion of their clients (52\%) was between 20 and 25 years old, which is similar to the findings of client intercept study undertaken at pharmacies.

\section{Conclusion}

These results demonstrate that training, especially through CTUs, can improve provider knowledge, attitudes and practices regarding EC. They also suggest that PSI's media campaign reached providers as well as potential clients, although providers' attitudes toward "misuse" may still be informed by negative media coverage. Nonetheless, these findings show that more work is needed to ensure that quality EC services are consistently delivered across the country; more trained providers are needed and services must be equally as accessible to adolescents and non-rape survivors. 


\section{INITIATIVE OUTCOMES}

As demonstrated above, the initiative was successful in improving provider capacity to provide EC and increasing public awareness of the method. While these accomplishments are notable, they serve as an intermediary step to the initiative's final objective of increasing utilization of EC.

Over the life of the initiative, EC use increased dramatically in both the public and private sectors. It is important to note, however, that such growing demand cannot be directly or solely attributed to the interventions outlined above. The popularity of EC in Kenya is due to a wide variety of factors, including increased supply in the private sector, greater attention in the media and improved provider comfort with the method. The combination of these conditions is likely to have contributed to the increased use documented below.

\section{Increased knowledge and use of EC among Kenyan women}

As indicated in Table 2, both knowledge and use of EC among Kenyan women doubled from baseline to endline. By 2009, 56\% of surveyed women between the ages of 18-30 knew of EC and 10\% of them had ever used it themselves. This confirms the public perception that the popularity of EC is growing in Kenya, but it does not indicate that such use has reached 'epidemic' proportions. The pharmacy intercept study also demonstrated that the majority of these users were young women between 20-29 years, and not young adolescents as often portrayed in the media.

\section{Increased sales of EC in the private sector}

Because the majority of Kenyan women who use EC obtain it through pharmacies, the most reliable measure of $\mathrm{EC}$ use in Kenya is private sector sales figures. In order to assess demand for EC, the Council tracked sales of the major distributors over the life of the initiative. To do this, Council staff negotiated agreements for access to this sensitive proprietary data, which stipulated that the sales figures of individual products remain confidential. To comply with this, Figure 13 provides composite data for all four brands sold in Kenya from 2007 to 2009.

Figure 13: National Sales of 4 major EC brands, over project life

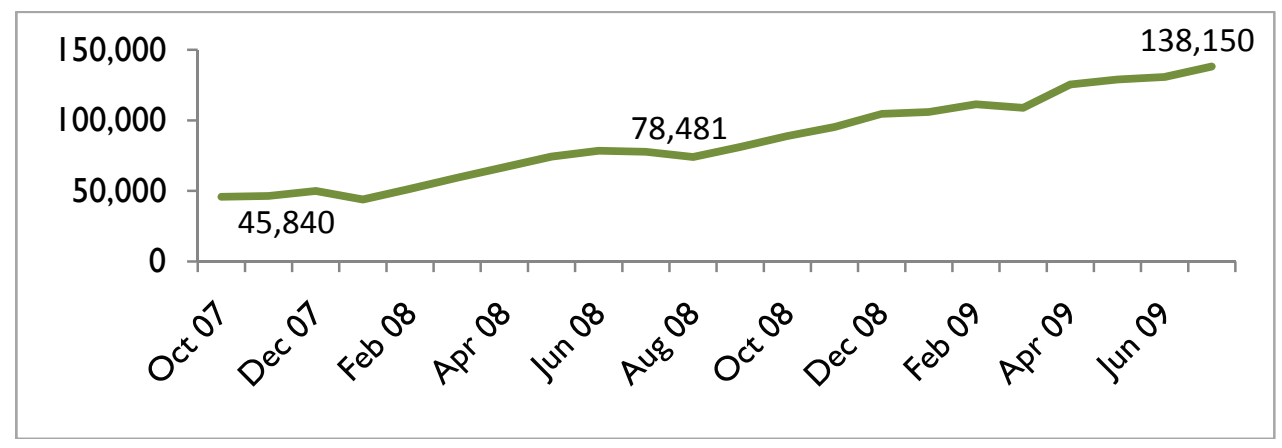


As figure 13 demonstrates, monthly EC sales have increased steadily over the life of the initiative. By July 2009, a reported 138,150 units were sold across the country in that month, which represents a more than three-fold increase from October 2007 (45,840 units).

Contributing to such a rise in sales has been the introduction of several new products on the market. During the initiative, the number of brands on the market has increased from 3 to 6 , indicating robust demand for the method.

\section{Increased distribution in the public sector}

Data obtained on public sector consumption demonstrates a similar trend, although the figures are less reliable. While the Council's efforts to track consumption at the facility-level were undermined by poor record-keeping, the APHIA II partner in Western Province was able to monitor utilization in select facilities. These facilities saw a $1525 \%$ increase in distribution of EC from 2007 to 2008, jumping dramatically from 143 doses to 2,324 .

Table 9 contains KEMSA data on the number of EC stocks issued from the central storehouse to the districts. These numbers represent orders from the district level, and approximate demand for EC across the country. Due to stock-outs and delayed shipments, issues in 2008 were lower than in 2007.

Table 9: Quantities of EC issued to districts and projected requirements, 2007-20 I 0

\begin{tabular}{|c|c|}
\hline Year & Quantities issued \\
\hline 2007 & 516,600 \\
\hline 2008 & 371,250 \\
\hline 2009 & $619,350^{*}$ \\
\hline 2010 & $1,186,800^{*}$ \\
\hline
\end{tabular}

* projected

Reflecting the growing need for EC, however, MOH projections for 2009 and 2010 indicate significantly higher figures. The challenge now is to ensure that the $\mathrm{MOH}$ has adequate stocks to meet this projected demand. 


\section{CONCLUSIONS}

Overall, the initiative was successful in achieving its primary objectives of increasing levels of awareness and correct use of EC and improving providers' capacity to deliver the method. Just as importantly, it has also created a body of knowledge on the process of mainstreaming EC at a national level and developed an evidence base for advocacy within Kenya and across Africa.

Among the key lessons learned are:

- Even negative media coverage on EC can be used effectively. As noted above, high profile articles on the "misuse" of EC have served to mobilize decision-makers around the need for increased public awareness and information on EC, especially for young people. It is likely that this positive response was informed by the evidence-based lobbying undertaken by initiative partners, which helped officials view EC as an important element of the country's public health program and recognize their responsibility to promote correct information on the method.

- Awareness and use of EC has increased dramatically in Kenya, but still remains low. Both awareness and reported use of EC increased dramatically over the life of the initiative. As indicated above in Table 2, in 2003, the KDHS indicated that less than one quarter of Kenyan women had ever heard of EC, by $2009,56 \%$ of women surveyed had ever heard of EC and 10\% had ever used the method. EC sales data, presented in Figure 13, also demonstrates an increased demand for the method. Similar trends are seen in the public sector, although the volumes are significantly lower.

Nonetheless, $44 \%$ of all eligible women are still not aware that EC exists, and misconceptions are rife among those who do know about the method. Of all women who know of EC, one-third believes that it causes abortion, and only about two-thirds know the correct timeframe for using the method. This indicates the need for continued education and awareness-creation on EC.

- Private sector pharmacies dominate EC provision in Kenya. Data collected under the initiative demonstrates that private sector pharmacies are the most common access point for EC. PSI's 2007 baseline survey found that $94 \%$ of women who had used EC in the past two years obtained it from pharmacies. In 2009, their endline survey found that while $83 \%$ identified pharmacies as a place to obtain EC, only $25 \%$ mentioned government clinics.

Within government clinics, the Council's 2007 record review found that $93 \%$ of the EC pills distributed in the previous 18 months were for sexual assault cases. While efforts under this initiative worked to strengthen EC provision within FP and ARH services, it is likely that a bias towards sexual assault provision still exists within many public health facilities.

In 2008, as indicated in Figure 2, national-level EC distribution through private sector pharmacies was approximately twice that distributed through the public sector. 
Figure 2: National Sales of EC vs. Public Sector Issues, 2008

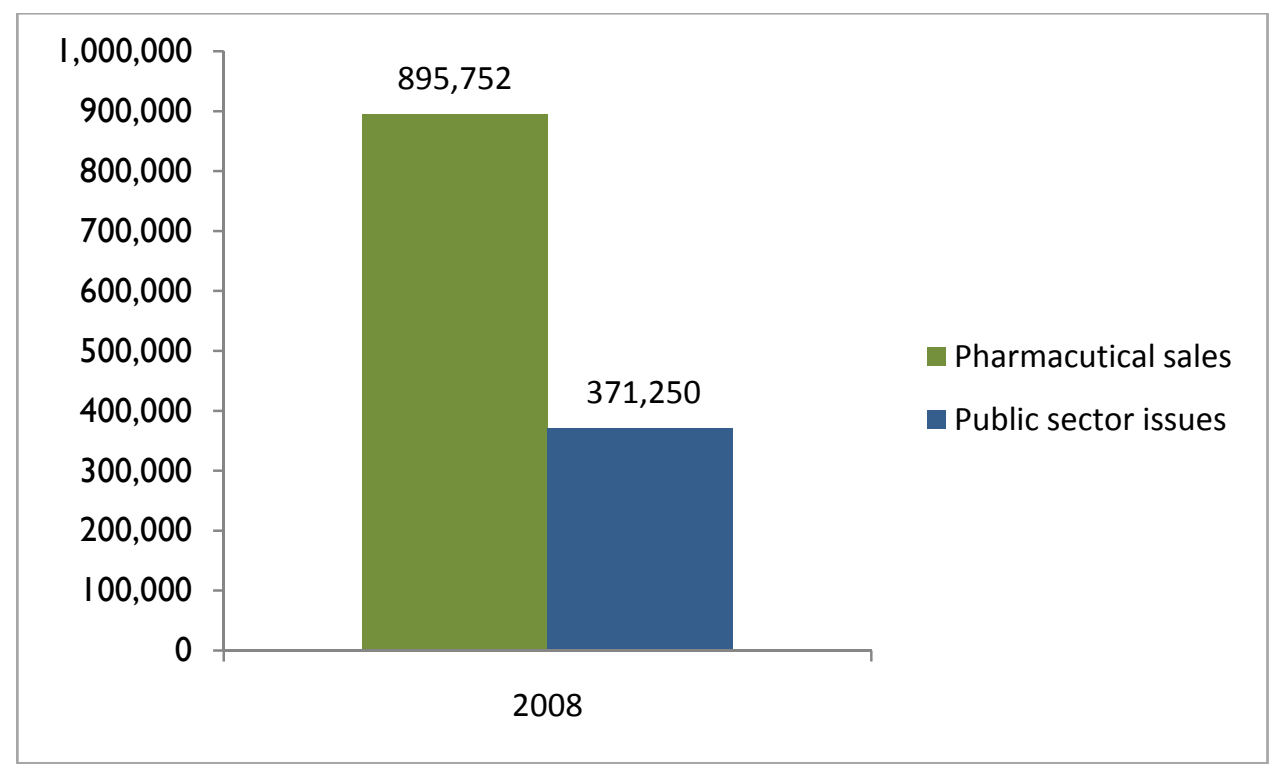

Qualitative research conducted with EC users indicated that they preferred to access EC through pharmacies because it was convenient, quick and confidential. Two-thirds (66\%) of women who purchased EC indicated that they had visited more than one pharmacy in an effort to maintain anonymity.

These findings suggest that the challenge in delivering quality EC services within pharmacies lies with balancing efforts to provide basic information on the method without compromising the qualities that make pharmacies so attractive to clients. Within the public sector, the challenge rests with increasing the speed and confidentiality of EC services within the context of larger FP programs.

- The majority of women who purchase EC from pharmacies are educated and employed.

Media reports have characterized EC users, especially those who access EC from pharmacies, as "girls as young as 14." Research conducted under this initiative, however, indicates this is not the case. In 2007, the Population Council conducted a client intercept study (where clients are interviewed after receiving a service) with 147 women who bought EC at pharmacies in urban pharmacies located in five provinces (Nairobi, Coast, Rift Valley, Nyanza and Western).

The results show that the average age of women surveyed was 25 years, and the majority was between $20-29$ years (72\%). None of these women reported that they were aged 14 or below, and only $11 \%$ of respondents were between the ages of 15-19. Most clients had a college/university level of education (61\%) and 61\% were currently employed (including self-employment). About two-thirds (65\%) were either married/cohabiting or single but in a steady relationship, but most women (57\%) also reported engaging in sex on an infrequent or irregular basis. A significant proportion (41\%) reported having at least one child. 
- Some Kenyan women have used EC more than once in a month, but repeat users are less informed about the method

Respondents in the 2007 client intercept study were asked about the number of times they had used EC in the past six months, frequency of use in relation to sexual activity, and time since last purchase of EC. The categorization of "repeat use" is based on the last question, and is defined as a client who has bought EC at least once previously in the past one month.

Data indicate that a majority $(58 \%)$ of women who had purchased EC had done so two or more times in the last month. Most of these purchasers (74\%) stated that they used EC as their only method during their last act of sex, and nearly as many $(70 \%)$ thought that EC were more convenient than other methods, while almost half preferred EC over methods such as daily contraceptive pills or injectables.

While repeat use of EC may be a conscious decision, it is not necessarily an informed one. The data also demonstrate that women who repeatedly used EC had greater misperceptions about the method's mechanism of action and efficacy. Nearly 60 percent believed that EC are 100\% effective, and many incorrectly believed that it would cause infertility or abortion. Overconfidence in EC's efficacy is likely to be one factor underpinning repeat use, with the benefits of convenience in the short-term outweighing perceived long-term consequences.

It is important to note that no significant negative health consequences have been associated with repeat use of EC. ${ }^{19}$ Current national and international guidelines, however, do not encourage reliance on EC as a regular method of FP. According to the World Health Organization, recurrent use of EC indicates the need for further counseling on contraceptive options. ${ }^{20}$ No conclusive evidence is available on the efficacy of EC if taken more than once in a cycle.

\section{- Pharmacies can provide better EC services with minimal investment}

Given the key role pharmacies currently occupy in the provision of EC in Kenya, and the demonstrated need for better client counseling, innovative efforts are needed to improve EC services within pharmacies.

The strategy for providing basic information to pharmacy clients tested under this initiative demonstrated promising results. Results of this intervention indicated that,

\footnotetext{
${ }^{19}$ United Nations Development Program/ United Nations Population Fund/ World Health Organization/ World Bank Special Programme on Research, Development and Research Training on Human Reproduction. Task Force on Post-Ovulatory Methods of Fertility Regulation. Efficacy and side effects of immediate postcoital levonorgestrel used repeatedly for contraception. Contraception 2000; 61:303-8.

${ }^{20} 20$ World Health Organization. Medical eligibility criteria for contraceptive use, Third edition. Geneva: World Health Organization, 2004.
} 
when given basic information, pharmacy staff were more likely to provide basic information on EC (including when and how to use, mechanism of action, side effects and efficacy) and discuss other FP and RH services with clients. These results suggest that sales staff at private sector pharmacies can deliver better EC services, if given the proper tools. It also indicates that extensive, and often costly, training efforts are not needed to improve services within pharmacies.

- Integrating skills and knowledge on EC into existing pre-service and in-service training programs can enhance public sector provision

Under the initiative, efforts focused on integrating EC into existing pre- and in-service training programs in a cost-effective and sustainable manner. With minimal resources, modules on EC were inserted into ongoing trainings conducted by APHIA II partners and in the regular MOPHS Contraceptive Technology Updates (CTUs), and evaluation data showed increased knowledge among trained providers. Perhaps the most strategic investment was in pre-service training, where limited technical and financial support enabled the integration of ECP into the revised Nursing Council's curriculum, ensuring that all future nurses will receive instruction on EC.

These experiences demonstrate that existing FP and RH initiatives can be successfully used to promote knowledge on EC. They also underscore the utility of integrating EC into existing activities, which is more-cost effective than stand-along trainings and promotes the principle that EC should be addressed in the context of comprehensive FP and post-rape care services.

- Active advocacy is necessary to ensure adequate EC stocks in the public sector.

Supply sustainability of all contraceptives, especially EC, remains a major challenge for the Kenyan government. Continued or sustained stock-outs would undermine the gains made during this initiative, and limit the impact of the policy and program changes that have been undertaken in recent years. As knowledge of EC increases throughout the country, so will supply requirements, and efforts to ensure sufficient commodities should continue.

Under the leadership of the DRH, advocacy efforts ensured that EC was included in the national contraceptive security plan and subsequent procurements. Since 2005, UNFPA has donated approximately 1,100,000 units to the MOPHS. In 2009, the MOPHS committed its own funds to purchase the country's largest procurement of EC to date of $5,875,000$ units. 


\section{RECOMMENDATIONS}

At this point, it is critical to sustain and consolidate the positive developments realized under the initiative. To do this, it is necessary to more fully engage the donors and civil society to support the government's renewed commitment to increasing public awareness and to ensuring quality EC services in both the public and private sector. It is also important to maintain the full involvement of the private sector in continued efforts to improve EC provision, including the Pharmaceutical Society of Kenya, Pharmacy and Poisons Board and the growing number of EC distributors. With the collaboration of these actors, the following efforts should be made:

1. Efforts to create public awareness and correct knowledge of EC should be continued. While knowledge of ECPs is increasing in Kenya, many potential beneficiaries are still unaware of the method and many others are misinformed. Accurate public information and education is critical for encouraging correct use of ECPs. It is important, therefore, to include messages on ECPs in comprehensive FP communication campaigns. This can be achieved by integrating the existing Tulia materials and messages into the national $\mathrm{RH}$ communication strategy operational plan, and in the DRH's community education and communication activities. The media can also play a critical role in creating correct public perceptions of the method, and should be regarded as a partner in these activities.

2. Professional associations, including the Pharmaceutical Society of Kenya and the Kenya Pharmaceutical Association, should continue educating their members on proper ECP provision. Given the central role pharmacies play in ECP access in Kenya, professional associations should work to ensure that their members are aware of strategies for ensuring clients are provided with the information they need to make informed decisions on ECP use. Such strategies need not be costly or time-intensive; this initiative demonstrated one model for increasing information provision in pharmacies, and others are likely to be feasible. At a minimum, the professional associations should include informational sessions and discussions on ECPs at all general meetings.

3. All MOPHS training partners should ensure that EC is integrated into all trainings on FP, RH, adolescent health or post-rape care. Numerous local and international NGOs assist the MOPHS with provider training. These partners' contributions can also be used to increase knowledge on EC, with as little as two additional hours of instruction for trained health care providers. The DRH should integrate existing training materials and job aids into a standardized module on EC to ensure that all partners offer uniform, high-quality instruction.

4. All pre-service training institutions and bodies should include EC provision in their curricula and examinations. Pre-service training is necessary to ensure that the next generation of Kenya's health professionals are well-equipped to provide this important and increasingly popular method. To do this, the country's leading medical pre-service training institutions must revise their curricula to reflect the MOPHS' renewed emphasis on quality EC provision.

5. The MOPHS, donors and partners should continue to ensure that adequate EC supplies are available in the public sector. Adequate stocks are essential in ensuring the success of public sector EC provision. Remarkable progress towards this has been achieved through the inclusion of EC in the government's FP commodities procurement and 
security plans. It is recommended that donors and other MOPHS partners continue to support the government to ensure that this emphasis on stock sustainability is maintained. Donors can also encourage their partners to integrate EC issues in their reproductive health communications, service delivery, logistics, trainings and research programs, and to explore innovative ways to strengthen private sector provision.

6. All stakeholders should promote the Kenyan experience as a model for the region. Kenya is at the forefront of EC programming in the region, and should be recognized for its vision and commitment to mainstreaming the method. As such, the Kenyan experience is well-suited to serve as a model for other countries on the continent interested in mainstreaming EC services. While Kenya may have a longer history with the method than other African countries, EC is rapidly becoming widely available in pharmacies across the continent due to the aggressive expansion of new products. As a result, countries such as Uganda, Botswana, Ghana, Nigeria and Malawi are now beginning to grapple with public concerns over repeat use. At the same time, public sector provision is also increasing as more countries emphasize EC as a core element of post-rape care. The lessons learned from Kenya can serve as an invaluable resource to these countries. 


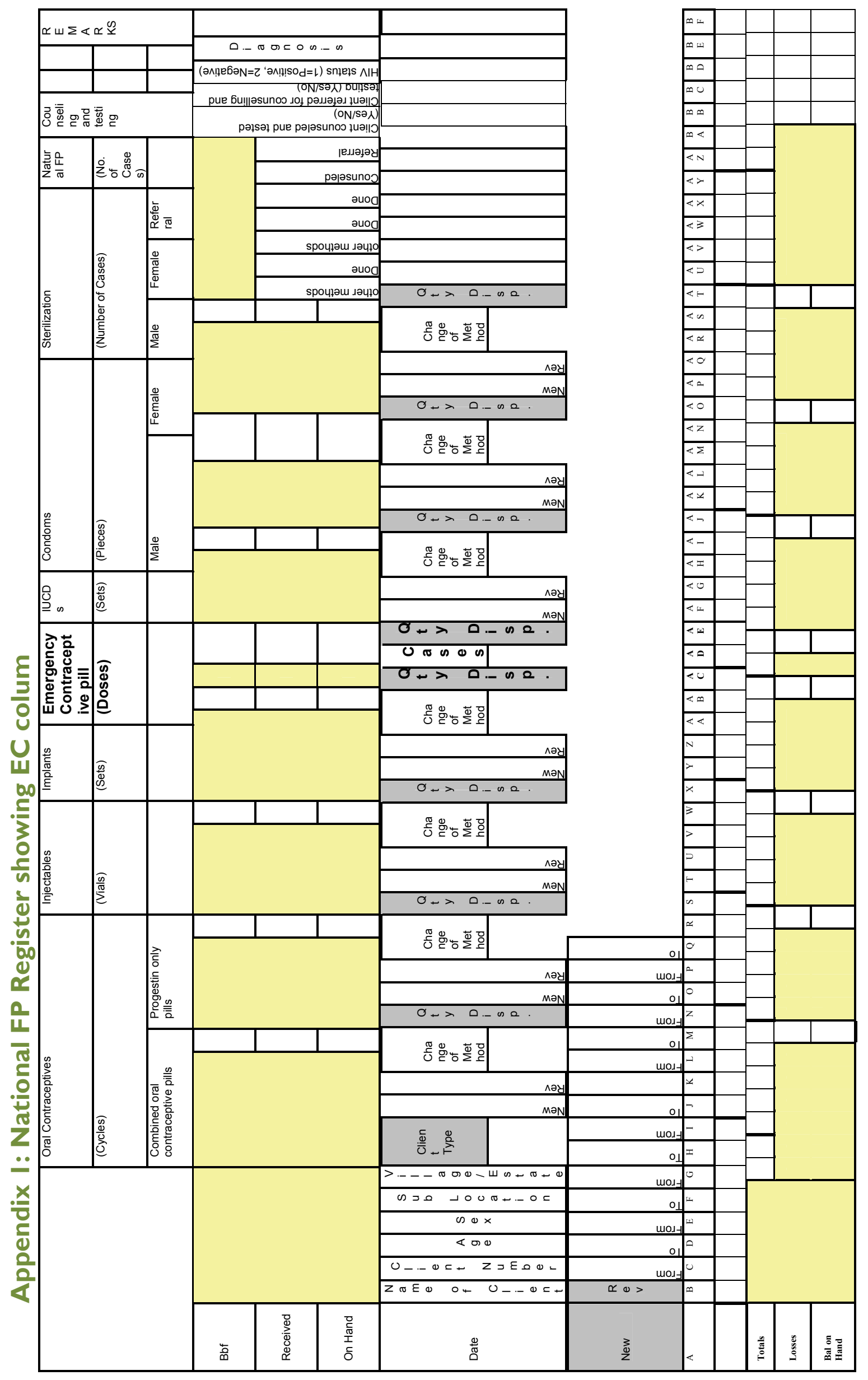

